\title{
APPROACH, AVOIDANCE, AND PSYCHOPATHOLOGY: CLARIFYING THE RELATIONS BETWEEN BIS/BAS SENSITIVITY AND SOCIO-EMOTIONAL FUNCTIONING IN CHILDHOOD
}

\author{
by \\ Kingsbury, Adam \\ A thesis submitted to \\ the Faculty of Graduate and Postdoctoral Affairs \\ in partial fulfillment of the requirements for the degree of \\ Master of Arts \\ in \\ Psychology
}

Carleton University

Ottawa, Canada

(C)2010 Adam Kingsbury 


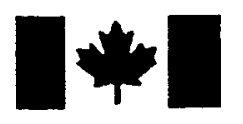

\author{
Library and Archives \\ Canada \\ Published Heritage \\ Branch \\ 395 Wellington Street \\ Ottawa ON K1A ON4 \\ Canada
}

Bibliothèque et

Archives Canada

Direction du

Patrimoine de l'édition

395 , rue Wellington

Ottawa ON K1A ON4

Canada
Your file Votre référence
ISBN: $978-0-494-71681-6$
Our file Notre référence
ISBN: $978-0-494-71681-6$
NOTICE:

The author has granted a nonexclusive license allowing Library and Archives Canada to reproduce, publish, archive, preserve, conserve, communicate to the public by telecommunication or on the Internet, loan, distribute and sell theses worldwide, for commercial or noncommercial purposes, in microform, paper, electronic and/or any other formats.

The author retains copyright ownership and moral rights in this thesis. Neither the thesis nor substantial extracts from it may be printed or otherwise reproduced without the author's permission.
AVIS:

L'auteur a accordé une licence non exclusive permettant à la Bibliothèque et Archives Canada de reproduire, publier, archiver, sauvegarder, conserver, transmettre au public par télécommunication ou par l'Internet, prêter, distribuer et vendre des thèses partout dans le monde, à des fins commerciales ou autres, sur support microforme, papier, électronique et/ou autres formats.

L'auteur conserve la propriété du droit d'auteur et des droits moraux qui protège cette thèse. $\mathrm{Ni}$ la thèse ni des extraits substantiels de celle-ci ne doivent être imprimés ou autrement reproduits sans son autorisation.
In compliance with the Canadian Privacy Act some supporting forms may have been removed from this thesis.

While these forms may be included in the document page count, their removal does not represent any loss of content from the thesis.
Conformément à la loi canadienne sur la protection de la vie privée, quelques formulaires secondaires ont été enlevés de cette thèse.

Bien que ces formulaires aient inclus dans la pagination, il n'y aura aucun contenu manquant.

\section{Canadä}


Approach, Avoidance, and Psychopathology

\begin{abstract}
Gray's Reinforcement Sensitivity Theory posits different brain systems that regulate approach and avoidance motivations and behaviours. The Behavioural Inhibition System (BIS) has been hypothesized as the neurological basis of anxiety. The Behavioural Activation System (BAS) is sensitive to rewards and is thought to be responsible for approach behaviours. The purpose of this study was to investigate the associations between BIS, BAS, and internalizing problems in childhood. Participants were 396 children (aged 9 to 13) from elementary schools in Ottawa. Children participated in two testing sessions, completing an assessment of BIS/BAS sensitivity, as well as internalizing problems. Parents also rated child internalizing and externalizing problems. Among the results, it was found that BIS sensitivity was positively related to depression, anxiety, and loneliness, and negatively related to perceived self-concept. BIS sensitivity also predicted parent-report emotional problems, and negatively predicted externalizing problems. BAS sensitivity, however, was not related to any of the measures.
\end{abstract}




\section{Acknowledgements}

I would like to take this brief opportunity to give recognition to those who facilitated the writing of this thesis. Firstly, to my wonderful supervisor, Dr. Robert Coplan, who has been my role model and inspiration over the past few years, and who has significantly helped make me the student and person that I am today. To my incredible parents, who have provided limitless support and love throughout my entire life, and who have always encouraged me to follow my instincts. To my younger brother, Brady, for being the best friend anyone could ask for, and for always keeping me humble. To all of the lab members, both past and present, who worked diligently to collect data for the past three years - without the co-operation and companionship, none of this would have been possible. Lastly, to my beautiful wife-to-be, for being a bottomless source of love, support, encouragement, and for always believing in me, no matter how tough things may seem. 
Approach, Avoidance, and Psychopathology

Table of Contents

Abstract

ii

Acknowledgements

iii

List of Tables

$\mathrm{v}$

List of Appendices

vi

Introduction

1

Methods

25

Results

30

Discussion

39

References

57

Appendices

67 


\section{List of Tables}

Table 1: Correlations between BIS, BAS and demographic variables 31

Table 2: Intercorrelations among all study variables. 33

Table 3: Descriptive statistics of study variables. 34

Table 4: Summary of hierarchical regression analyses predicting internalizing outcomes from BIS and BAS sensitivity.

Table 5: Summary of hierarchical regression analyses predicting parent-reported outcomes from BIS and BAS sensitivity. 


\section{List of Appendices}

Appendix A: Parental Information Package

Appendix B: BIS/BAS Scales

Appendix C: Social Anxiety Scale for Children

Appendix D: Child Depression Inventory 75

Appendix E: Loneliness and Social Dissatisfaction Questionnaire

Appendix F: Self-Description Questionnaire

Appendix G: Strengths and Difficulties Questionnaire 
Approach, Avoidance, and Psychopathology 1

Approach, Avoidance, and Psychopathology: Clarifying the Relations Between BIS/BAS

Sensitivity and Socio-emotional Functioning in Childhood

The notion that aspects of personality are related to emotional outcomes is not a new idea. Indeed, the major personality theories all implicate certain characteristics in the development of mental health issues (e.g., Theory of Arousal, Eysenck, 1967; Big 5 Model, Costa \& McCrae, 1985). Developmental psychologists have also postulated that emerging personality characteristics in childhood may be associated with developmental psychopathology (e.g., Blair, 2003; Blair, Peters, \& Granger, 2004; Colder \& O'Connor, 2004; Coplan, Wilson, Frohlick, \& Zelenski, 2006; Field, 2006; Muris, Meesters, Kanter, \& Timmerman, 2005; Slobodskaya, 2007). Although there are many different approaches to the study of personality, the biologically derived Reinforcement Sensitivity Theory (RST; Gray, 1970) of personality provides a unique account to examine relations between psychopathology and innate character traits.

Gray $(1970 ; 1982)$ posited the existence of different control systems in the brain that regulate approach and avoidance behaviours. The Behavioural Inhibition System (BIS) is responsible for goal conflict resolution and has been hypothesized as the neurological basis for the experience of anxiety. There is a large body of empirical research linking the BIS to certain types of psychopathology. For example, low BIS sensitivity has been associated with attention-deficit hyperactivity disorder (Quay, 1997) and psychopathy (Fowles, 1980). As well, high BIS sensitivity has been linked with symptoms of anxiety in both clinical and unselected populations (e.g., Beevers \& Meyer, 2002; Coplan et al., 2006; Kimbrel, Nelson-Gray, \& Mitchell, 2007). 
In contrast, the Behavioural Activation System (BAS) is mediated by dopaminergic pathways in the brain and hypothesized to be the neurological basis of impulsivity. The BAS is sensitive to reward stimuli and is thought to be responsible for approach motivation and behaviours. High BAS sensitivity has been linked to conduct disorder in children (Quay, 1993) and low BAS sensitivity has been associated with feelings of depression (Depue, Krauss, \& Spoont, 1987). Thus, it appears as though extreme sensitivity of both the BIS and BAS tend to be related to psychopathological outcomes. However, it has been recently hypothesized that unique combinations of the BIS and BAS subsystems may also contribute to the development and maintenance of psychopathology (Bijttebier, Beck, Claes, \& Vandereycken, 2009). For example, Corr (2002) proposed the joint subsystems hypothesis which suggests that the BIS and the BAS work in an interactive manner to influence behaviour, rather than being orthogonal and independent systems (as originally proposed by the early RST model; Gray, 1987).

With the exception of a handful of studies (e.g., Blair, 2003; Colder \& O'Connor, 2004; Coplan et al., 2006; Field, 2006) all previous research on the relation between BIS/BAS sensitivity and psychopathology has been conducted with adult samples. As such, the purpose of this study was to explore the contribution of the BIS and BAS in the development of internalizing difficulties (e.g., anxiety and depressive mood) in childhood. Further, drawing upon the postulation of the joint subsystems hypothesis, interactions between BIS and BAS were also explored in the prediction of child socioemotional functioning. In particular, it was speculated that BAS sensitivity would moderate the associations between BIS and internalizing problems. Conceptual \& Historical Overview of Reinforcement Sensitivity Theory 
The formulation of Reinforcement Sensitivity Theory (RST) was developed by first identifying the brain structures that may be associated with personality traits, and then relating these structures to existing measures of personality (Corr, 2008). Contrary to other approaches at the time, Gray believed that personality was defined by the brainstructures associated with behaviour. Historical influences in the development of RST can be traced back to the pioneering research of Eysenck (1967) and his Theory of Arousal.

Eysenck's theory of extraversion. Hans Eysenck's $(1957,1967)$ theory took a different approach to the development of an explanation of human personality. Whereas Gray (1982) was interested in identifying the neural mechanisms associated with personality, Eysenck's 'top-down' approach attempted to identify systems based on the structure of observed personality dimensions (i.e., Extraversion; Corr, 2008). It is important to note that the approaches of Gray and Eysenck are considered to be complimentary in nature; each theory attempts to study personality at different levels of analysis (Corr, 2008). In an extensive review of the history of RST, Corr (2008) discusses the fundamental differences between the theories of Gray and Eysenck by examining the problems that were present in psychology during the $20^{\text {th }}$ century.

Eysenck's arousal theory of Extraversion (1967) was largely based on the drive reduction theory postulated by Hull (1952), which suggested that the single factor of 'drive reduction' was responsible for learning and reinforcement. Eysenck (1967) proposed that extraverts (i.e., individuals with low baseline levels of arousal) and introverts (i.e., individuals with high baseline levels of arousal) differ in the sensitivity of their cortical arousal system due to different response thresholds. As compared to 
extraverts, introverts are more aroused at baseline due to lower cortical response thresholds. However, the relation between potential arousal-induction and actual arousal is moderated by transmarginal inhibition, which is a protective mechanism in the brain that reduces the link between stimulus intensity and behaviour when faced with overwhelming stimuli. Under low stimulation, introverts are more aroused than extraverts, but at higher levels of stimulation, introverts become over-aroused, leading to the activation transmarginal inhibition. When this occurs, introverts will experience lower subsequent increments in arousal levels compared to extraverts. On the contrary, extraverts are thought to show low arousal under low levels of stimulation, but should show higher increments in arousal under increasing stimulus intensity. Later, a second dimension, Neuroticism was added to Eysenck's theory of arousal (Corr, 2008). Neuroticism refers to emotional instability and is thought to be linked to the limbic system.

RST: Original formulation. Reinforcement Sensitivity Theory (Gray, 1970) began as an alternative perspective to Eysenck's (1967) theory of extraversion (Corr, 2008). In particular, Gray (1970) posited two dimensions consisting of combinations of Extraversion and Neuroticism in factor space and proposed neurological bases of these constructs. Gray's primary argument was that Extraversion and Neuroticism should be rotated counter-clockwise $30^{\circ}$, to represent the axes defined as 'punishment sensitivity' and 'reward sensitivity'. These new axes represented combinations of Neuroticism and Extraversion, classified as 'anxiety' and 'impulsivity' (Corr, 2008).

Although Gray's (1982) original theory has been revised since its inception, much of the new theoretical framework is rooted in the original formulation (McNaughton \& 
Approach, Avoidance, and Psychopathology 5

Corr, 2008). In the original theory, the BIS was posited to be sensitive to signals of punishment, non-reward, novel stimuli, as well as innate fear-inducing stimuli. The role of the BIS was thought to be to produce an increment in arousal, an increase in attention, and stimulate avoidance behaviour. The septo-hippocampal system is the main neurological structure implicated as the primary anxiety-center by Gray (1987) in the original RST. The septo-hippocampal system was postulated to be the center of the anxious response due to the similar behavioural output associated with both anxiolytic drugs and hippocampal lesions (McNaughton \& Corr, 2008). The posterior cingulate cortex appears to be specifically involved in behavioural inhibition (Berger, Weikart, Bassett \& Orr, 1986).

The BAS, conversely, was thought to be responsive to incentives and rewards present in the environment. According to this original model, once the BAS recognizes any stimulus as potentially rewarding, it activates approach behaviour toward the rewarding stimulus. The BAS is hypothesized to lie within dopaminergic-rich areas of the brain such as the frontal and striatal regions (Pickering \& Smillie, 2008). Neuroscientific studies in personality have shown dopaminergic cell activity in the ventral tegmental area when an animal is exposed to both primary and conditioned rewarding stimuli (see Schultz, 1998 for a full-review). The projections of these cells are largely directed toward the striatum, prefrontal cortex, and limbic structures (Pickering \& Smillie, 2008).

RST: Revision. After further animal work, Gray (1987) added a third system to RST called the Fight-Flight System (FFS). The FFS was posited to respond to unconditioned, innately aversive stimuli, in contrast to the BIS, which responds to conditioned aversive stimuli. Under this reworked model, if escape is possible, the FFS 
elicits avoidance behaviour (flight); if escape is not possible, the FFS will trigger aggressive behaviours (fight). Recently, Gray and McNaughton (2000) published an extensive revision to Reinforcement Sensitivity Theory which primarily reworked the role of the BIS and added a third dimension to the FFS - freezing behaviour (this system is now referred to as the Flight-Flight-Freeze System; FFFS). The FFFS can be classified as the defensive-avoidance system of the brain, with its main function being to motivate avoidance behaviours in response to any conditioned or unconditioned aversive stimuli (McNaughton \& Corr, 2008). The lowest neural level at which defensive behaviour is controlled is in the periaqueductal gray, which is primarily responsible for undirected (i.e., fleeing without regard to direction) escape behaviours and panic response (Deakin \& Graeff, 1991). The periaqueductal gray, has also been implicated in defensiveaggressive reactions (Bandler, Price and Keay, 2000), and rage (Bandler, 1982). The medial hypothalamus, another neural substrate implicated in the FFFS, is responsible for directed (i.e., a planned direction) escape behaviours (Deakin and Graeff, 1991). The amygdala is responsible for controlling both active avoidance and phobic avoidance, and seems to play a part in both fear and anxious responses (LeDoux, 1994; McNaughton \& Corr, 2008). The anterior cingulate cortex is involved in complex active avoidance largely stemming from FFFS outputs (McNaughton \& Corr, 2008). Lastly, in the prefrontal cortex, both the dorsal and ventral stream have been implicated as the highest level of neural structures involved in the BIS/FFFS (McNaughton \& Corr, 2008).

To understand the changes to the theory it is important to clarify the distinction between fear and anxiety. Although it is common practice in the literature to treat these constructs as functionally identical, McNaughton and Corr (2008) describe fear as a 
response resulting from the requirement to avoid danger. Anxiety, on the other hand, is a response resulting from the requirement to approach danger. As a result, the main factor that differentiates fear and anxiety can be referred to as 'defensive direction' (McNaughton \& Corr, 2008). Fear will direct an animal away from danger, and is insensitive to anxiolytic drugs. All of the behavioural correlates associated with anxiety, on the other hand, are sensitive to anxiolytic drugs (McNaughton \& Corr, 2008). When in an approach-avoidance conflict, anxiety will direct an animal toward danger, but with increased attention and heightened risk-assessment behaviours.

Under the revised RST (Gray \& McNaughton, 2000), the FFFS is thought to mediate all reactions to both conditioned and unconditioned aversive stimuli. Accordingly, the BIS is no longer considered a mediator between aversive stimuli and behaviour, but rather is thought to be responsible for goal conflict resolution in general. The new RST states that conflict between mutually exclusive goals occurs more than conflict between differing stimuli. Goal conflict then arises when two goals materialize along with an equal desire in an organism to approach both at the same time. McNaughton and Corr (2008) note that approach-avoidance tendencies are not the only conflicts that need to be resolved. For example, approach-approach and avoidanceavoidance conflicts also routinely arise. However, when motivation towards two goals are equally balanced, McNaughton and Corr (2008) suggest that evolution tends to favour risk aversion, as receiving a large reward is not beneficial in the long run if the potential of getting killed is equally high. Despite the recent advancements in the conceptualization of the RST subsystems, no measure currently exists that assesses the unique functioning 
Approach, Avoidance, and Psychopathology 8

of the FFFS. As result, the traditional notion of the BIS in the literature represents aspects of both the FFFS and BIS.

Traditionally, the BIS has been associated with the inhibition of behaviours. Although prepotent behaviours are inhibited in potentially threatening situations, these behaviours are typically replaced by special responses designed to resolve conflict (e.g., risk-assessment). With regards to how a decision is made, the BIS serves three essential functions when it detects a conflict: (1) both approach and avoidance are suppressed; (2) a bias toward avoidance is activated; and (3) risk-analysis behaviour is activated. Once this process has been initiated, the BIS acts in a subtractive manner, selecting the most appropriate action depending on newly obtained information (McNaughton \& Corr, 2008).

The major change to proposed BAS functioning stemming from the revised RST (Gray \& McNaughton, 2000) is that the BAS is now thought to be sensitive to both conditioned and unconditioned rewards (original RST only posited sensitivity towards conditioned rewards). Two processes appear to be in effect with respect to BAS-mediated behaviour. First, a motivational effect redirects behaviour towards sources of reward which can increase in intensity, and shapes the direction of behaviour when rewarding stimuli are present. Second, a learning \& reinforcement effect redirects attention towards reward, heightens arousal levels, and facilitates increased information processing (Pickering \& Smillie, 2008). In regards to personality research, it is assumed that the reactivity of the above processes will differ from person to person.

Although the BAS has been shown to be linked with positive affect (Fowles, 1993), recent research suggests that the BAS may also be linked with negative states such 
Approach, Avoidance, and Psychopathology 9

as frustrative non-reward (Carver, 2004). In an attempt designed to assess the effects of frustrative non-reward, Carver conducted an experiment on healthy undergraduate students where they were led to expect a reward based on a simple-task. Regardless of performance, all participants received identical feedback which indicated that they had not received any reward. Results suggested that feelings of sadness and frustration were related to an overactive BAS (Carver, 2004).

Joint Subsystems Hypothesis. Gray (1987) originally posited that the BIS and BAS were completely orthogonal systems and should therefore not be associated with each other. From this conceptual perspective, it would thus be expected that responses to reward should be the same at all levels of BIS, and that responses to punishment should be the same at all levels of BAS (Corr, 2001). According to Corr (2001), this view falls in line with the separable subsystems hypothesis. Gray (1982) posited the orthogonal nature of the BIS and BAS largely based on animal experiments. The behaviour observed in these experiments were typically approach-avoidance conflict situations where one system tended to dominate, thus leading to the assumption of exclusivity of behavioural control (Corr, 2001). In typical human experience, however, it is unlikely that reinforcing stimuli are powerful enough to completely suppress the function of the opposing system.

Corr (2001) argued that the possibility of the BIS and BAS to exert functionally interdependent effects exists under the principles of RST. According to the joint subsystems hypothesis, reward response would be highest in people with high BAS and low BIS reactivity, whereas aversive response would be highest in people with high BIS and low BAS reactivity. Behavioural outcomes are thought to be influenced by both the BIS and BAS, with motivational influences demonstrating an interactive nature (e.g., a 
high-reward situation coupled with a moderate amount of risk would reduce the rewarding influence of the situation). However, the direction of influence between the two systems is not parallel. Corr (2001) also postulated that the BIS may influence the BAS more than the BAS may influence the BIS. It is important to note that Corr (2001) did not suggest that the joint subsystems and separable subsystems hypotheses are mutually exclusive - rather, they are seen as complimentary theories each pertaining to different situations.

Corr (2002) predicted that the effects of the separable subsystems hypothesis would be present under three circumstances: (1) when strong appetitive/aversive stimuli are used; (2) when people with extreme BIS/BAS sensitivity are tested; and (3) in experimental situations that do not contain mixed reward and punishment cues. The joint subsystems hypothesis, however, would apply during normal human experience, and all other situations not meeting the listed criteria. Most human experiments use stimuli that are not as strong as those used in animal experiments, and thus the joint subsystems hypothesis is likely to apply in such situations. For the joint subsystems hypothesis to be valid, Corr (2002) asserted that it only needs to be assumed that behavioural output is the sum of inputs from both the BIS and the BAS.

Corr (2002) conducted a two-part study designed to provide empirical support for the joint subsystems hypothesis. In the first phase, fear potentiation (represented by startle response) was elicited while people were exposed to pleasant, neutral, and unpleasant images. Each participant was assessed for levels of anxiety and impulsivity (used as analogues of BIS and BAS respectively), and exposed to 12 images in each of the categories. Startle probes (a brief blast of white noise) were randomly presented in 
each category, and startle response served as the dependent variable. In high-anxiety/lowimpulsivity participants, startle responses during the unpleasant slides were the highest compared to all other groups. The reactions of the high-anxiety/high-impulsivity participants were the next strongest, followed by weak responses in the in the lowanxiety/low-impulsivity group, and a lack of a response in the low-anxiety/highimpulsivity group.

In the second phase of the study, Corr (2002) assessed the effects of BIS/BAS sensitivity on the number of errors made in a laboratory task. The rapid visual information processing task requires participants to detect three successions of odd or even numbers in a row, while recording the number of hits (correct responses) and the number of false-alarms (incorrect responses). One hundred and twenty adults were randomly assigned to one of four blocks comprised of two levels of arousal (caffeine/placebo) and two levels of reinforcement (punishment of errors/feedbackalone). Caffeine was hypothesized to enhance the effects of the subsystems. In the feedback condition, participants were instructed to be as accurate and fast as possible when answering. The same instructions were given in the punishment group, but with the caveat that money would be deducted for every incorrect response given (participants in this condition were given $£ 5.00$ at the beginning of the experiment). Results of this part of the study showed that impulsive individuals (i.e., high BAS) who were aroused by caffeine, who also had no effective inhibitory mechanisms (i.e., low BIS), showed the greatest number of false alarms compared to all other groups. Corr (2002) suggested that the patterns of results indicated that anxiety antagonized the effects of impulsivity. Measurement of $B I S / B A S$ 
In human experiments designed to test RST-derived hypotheses, BIS/BAS sensitivity has typically been assessed by examining behavioural, psychophysiological, or psychometric correlates assumed to be represent the BIS/BAS subsystems (Torrubia, Avila, \& Caseras, 2008). According to Torrubia et al. (2008), the lack of standard measures makes it difficult to compare results across studies. With regards to self-report assessments, measures not derived directly from RST have been used to examine BIS/BAS sensitivity in humans (e.g., measures of the Eysenckian traits of Neuroticism and Extraversion). Furthermore, measures related to Anxiety and Impulsivity have also been used to represent both the BIS and BAS respectively (Corr, 2001; Patterson, Kosson, \& Newman, 1987). More recently, assessments based directly from the RST framework have been designed in attempts to make research results more homogenous. Torrubia and Tobena (1984) developed the Susceptibility to Punishment Scale, the first attempt at a direct assessment of BIS sensitivity. Other later developed measures include the Gray-Wilson Personality Questionnaire (Wilson, Barrett, \& Gray, 1989) - the first to assess both BIS and BAS sensitivity, and the General Reward and Punishment Expectancy Scales (Ball and Zuckerman, 1990), which failed to show adequate validity (Torrubia et al., 2008).

By far, the most widely used measure to date is the Carver and White $B I S / B A S$ Scales (1994). The measure consists of seven items on a 4 point likert-type scale assessing BIS sensitivity and three separate subscales that address BAS sensitivity: Drive, Fun Seeking, and Reward Responsiveness. The four-factor solution was obtained after a factor analysis with oblique rotation was conducted by the original authors. The second most widely used measure was developed by Torrubia, Avila, Molto and Caseras (2001) 
entitled the Sensitivity to Punishment and Sensitivity to Reward Questionnaire (SPSRQ) using a dichotomous (Yes/No) format to measure both BIS and BAS sensitivity. RST and Psychopathology

Personality dimensions have long been hypothesized to be related to psychopathology. For example, Hans Eysenck developed the constructs of Extraversion and Neuroticism based on statistical data derived from 'war neurotics' (Corr \& McNaughton, 2008). Personality dimensions that lie on the extreme poles have been hypothesized to be linked to a number of different disorders. In regards to RST, extreme BIS/BAS sensitivity has been linked to anxiety, depression, bipolar disorder, psychopathy, attention deficit disorder, eating disorders, substance abuse, and personality disorders (Bijttebier, Beck, Claes, \& Vandereycken, 2009).

Internalizing problems. Most of the research linking BIS/BAS to aspects of psychopathology has focused on internalizing problems (i.e., anxiety, depression). Fowles (1988) was among the first to hypothesize that depression might be associated with low BAS sensitivity and anxiety related to high BIS sensitivity. Research with adult populations has shown a high degree of co-morbidity between anxiety and depression (Di Nardo \& Barlow, 1990; Sanderson, Di Nardo, Rapee, \& Barlow, 1990). The differences and similarities between anxiety and depression are discussed in the Tripartite Model (Clark and Watson, 1991). This model states that although both anxiety and depression both share a general level of negative affect, depression is uniquely characterized by having low levels of positive affect.

Although Clark and Watson (1991) originally proposed that hyperarousal differentiated anxiety from depression, later research concluded that hyperarousal 
differentiated panic disorder, but not necessarily other anxiety disorders, from major depression (Brown, Chorpita, \& Barlow, 1998, Zinbarg et al., 1994; Zinbarg \& Barlow, 1996). Zinbarg and Yoon (2008) have recently argued that the fundamental differences between depression and anxiety may lie in BAS sensitivity. Depression is typically characterized by a loss of hope in being able to cope effectively, suggesting the presence of low positive affect/BAS activity. Anxiety, on the other hand, involves extensive preparation for efforts to cope (irrespective of effectiveness of certain coping methods) which suggests at least a moderate amount of positive affect/BAS activity.

Johnson, Turner, and Iwata (2003) conducted the first longitudinal epidemiological study of this hypothesis using a representative sample of $n=1,803$ young adults (aged 19-21 years). Each participant was given a diagnostic interview, and levels of BIS/BAS sensitivity were assessed using the BIS/BAS Scales (Carver \& White, 1994). Results showed that BIS sensitivity was related to higher diagnoses of both anxiety and depression, and the BAS Fun-seeking scale was related to drug and alcohol problems.

McNaughton and Corr (2008) hypothesized that symptoms associated with anxiety-based psychopathology may be generated in a variety of ways. For example, the symptoms one experiences (e.g., panic, phobia) may be an accurate reaction to corresponding stimuli (e.g., the panic experienced in a car crash; fearing poisonous snakes after being bitten). Conversely, the symptoms themselves may be maladaptive and result from a hyper-sensitivity of corresponding neural-mechanisms. This line of reasoning suggests that some people with anxiety disorders may have their 
symptomatology generated by environmental stressors, malfunctioning neural structures, or a combination of both.

Externalizing problems. There is substantial research linking BIS/BAS sensitivity to internalizing difficulties. However, a smaller body of research also suggests that extreme sensitivity may also be related to externalizing problems, albeit with somewhat mixed results (Bijttebier et al., 2009). Quay (1997) suggested that an underactive BIS may be responsible for the hyperactive behaviours and tendencies displayed by those with ADHD. An underactive BIS fails to provide cues that lead to an inhibition of behaviours after punishing stimuli have been presented, resulting in the inappropriate behaviours seen in those with ADHD. Other research has also suggested that an overactive BAS may instead be responsible for externalizing behaviours associated with ADHD (Nigg, 2001). Furthermore, Mitchell and Nelson-Gray (2006) also found that BAS sensitivity was related to ADHD symptoms, whereas BIS sensitivity was not. RST Research in Children

Most of the research examining the relation between BIS/BAS sensitivity and psychopathology has been conducted with samples of adults (Bijtebbier et al., 2009). This focus on adults is likely due to the fact that the most common measure used to assess BIS/BAS sensitivity was designed exclusively for use with adults (i.e., the $B I S / B A S$ Scales; Carver \& White, 1994). Recent research, however, has extended this work to examine younger populations. Two approaches have been taken to assess BIS/BAS in children. The first has relied upon parental reports (e.g., Blair, 2003; Blair, Peters, \& Granger, 2004) and the second has adapted adult self-report measures for use with children (e.g., Colder \& O'Connor, 2004; Coplan, Wilson, Frohlick, \& Zelenski, 
2006; Field, 2006; Muris, Meesters, Kanter, \& Timmerman, 2005; Slobodskaya, 2007). As described in the following sections, although the overall pattern of results of BIS/BAS research with children has mirrored the findings with adults, some important differences have also emerged.

Parent-report measures. Blair (2003) examined the relation between a parental version of the BIS/BAS Scales (Carver \& White, 1994) and teacher-reported behaviour in the classroom. Participants were 42 preschool-aged children from low SES backgrounds. Mothers of the children completed the BIS/BAS Scales to assess BIS and BAS sensitivity in the children. Overall, Blair (2003) found that the BIS scale positively correlated with parent reports of children's temperamental fearfulness. Furthermore, the drive, funseeking, and reward-responsiveness subscales of the BAS positively correlated with parent-reported temperamental anger. Surprisingly, the BIS scale was positively associated with teacher-rated social-emotional competence, but negatively associated with teacher reported on-task behaviour. With regards to the relation between the BIS and teacher reported social competence, Blair (2003) speculated that those children with lower thresholds for threat sensitivity might be more likely to avoid or peacefully resolve conflict, approach other children in a less-confrontational manner, and spend more time in close proximity to teachers. Children who regularly engage in these behaviours may be seen by the teacher as exhibiting higher levels of social competence as compared to those children with higher threat sensitivity thresholds.

In a follow-up study, Blair, Peters, \& Granger (2004) further investigated the utility of the parent-report version of the BIS/BAS Scales (Carver \& White, 1994). The sample consisted of 170 children from low SES backgrounds in rural areas. BIS and BAS 
sensitivity was assessed by maternal report. Results of the study found that BIS was positively correlated with temperamental anger, approach, and fear. BAS on the other hand, was correlated with temperamental anger and approach, but not fear. BIS scores were also associated with an increase in salivary cortisol levels during data collection as well as an increase in executive functioning. On the other hand, higher BAS scores were associated with a decrease in salivary cortisol levels during the assessment as well as lower scores on measures of executive functioning. Lastly, children with high BAS sensitivity showed greater baseline cortisol levels, irrespective of levels of BIS.

A person-oriented analysis was then conducted by Blair et al. (2004) to examine whether unique combinations of BIS/BAS (High-BIS/Low-BAS, etc.) would distinguish individuals who were characterized by only one extreme dimension on its own (see Bergman \& Magnusson (1997) for a complete description of person-oriented analysis). Median splits were conducted to form four distinct groups of combinations of BIS and BAS: (1) children below the mean on both BIS and BAS (low BIS/low BAS); (2) children with high BAS and low BIS (high BAS/low BIS); (3) children with high BIS and low BAS (high BIS/low BAS); and (4) children with both high BIS and BAS (high BIS/high BAS).

Children characterized by high BAS/low BIS showed a decrease in salivary cortisol over the assessment period. Conversely, individuals with high BIS/low BAS showed an increase in salivary cortisol. Those characterized by high BIS/high BAS, and low BIS/low BAS showed no cortisol changes during the experiment. Finally, high BAS/high BIS individuals performed lower on measures of executive function when compared to other groups. The authors speculated that the higher baseline levels of 
cortisol seen in those children with higher BAS reflect greater activity in the classroom. The higher executive functioning exhibited by those with high BIS levels reflect cognitive regulation that the author believe may be consistent with a shy, withdrawn personality. Of importance, the study failed to find any associations between BIS and teacher reported social competence similar to that found in Blair (2003).

Taken together, these findings support the notion that parental assessment of BIS/BAS sensitivity is indeed a predictor of adverse outcomes in childhood. Parentreport BIS sensitivity appears to be related to fear and an increase in arousal during interaction with others. Also, providing some indirect support for the joint subsystems hypothesis in childhood, results from Blair and colleagues' (2004) person-oriented analyses suggested that both the BIS and the BAS may work additively to 'cancel out' cortisol changes during exposure to stress.

Child self-report measures. Colder and O'Connor (2004) adapted an existing adult-self report measure (Sensitivity to Punishment and Sensitivity to Reward Questionnaire, Torrubia et al., 2001) to directly assess the independent strength of the BIS and BAS in children. Sixty-three children aged 9-12 years participated in the study. Confirmatory factor analysis suggested a 4-factor solution, with one factor representing sensitivity to punishment and three others relating to sensitivity to reward (impulsivity/fun seeking, drive, and reward responsiveness). Of note, this 4-factor solution is similar to what has been reported in the adult literature using the Carver and White (1994) BIS/BAS Scales. As well, parents were asked to report on their children's internalizing and externalizing behaviours. 
Results of the study indicated that lower sensitivity to punishment and higher impulsivity were related to more passive avoidance errors (Colder \& O'Connor, 2004). Sensitivity to punishment was also associated with greater response times during the punishment block of a reaction time task. Impulsivity/fun-seeking (but not drive or reward responsiveness) was related to externalizing problems. Finally, sensitivity to punishment was also predictive of internalizing problems. This is the only study that has used this particular measure to assess reward and punishment sensitivity with children. The other studies using self-report assessments with children have relied upon adapted versions of the BIS/BAS Scales (Carver \& White, 1994).

Muris et al. (2005) were the first to create an age-downward version of the Carver and White (1994) BIS/BAS Scales. Items on the BIS/BAS Scales were simplified to be more understandable for younger participants. A sample of 284 children (aged 8-12 years) completed the new questionnaire, as well as measures of Extraversion and Neuroticism. Internalizing and externalizing problems were assessed via both self-report and parent-report measures. Positive associations between Neuroticism and both BIS (strong relation) and BAS (weaker relation) were found. Extraversion was negatively related to BIS and positively related to BAS. A strong relation was also found between BIS and both parent and self-reports of anxiety and depression. More modest correlations were found between BAS and assessments of externalizing problems. However, some differences with adult literature were also reported. For example, Muris et al. (2005) reported a significant (albeit modest) positive correlation between BIS and BAS sensitivity. These findings were in contrast with previous studies in adults, which have indicated that BIS is not associated with BAS in general, and only slightly associated 
with BAS-Reward responsiveness (e.g., Jorm et al., 1999; Ross, Millis, Bonebright, \& Bailley, 2002). Muris et al. (2005) suggested that this result may be due to children's tendency towards a response bias in questionnaires (i.e., the tendency to score consistently high or low on dissimilar questionnaire items).

As well, whereas Carver and White (1994) found a four-factor solution for the $B I S / B A S$ Scales among adults (a single BIS scale, three scales for BAS), Muris et al. (2005) reported a two-factor solution in the sample of children, with a single factor for both BIS and BAS. A few different explanations were offered for this inconsistent factor structure. To begin with, although most researchers agree that the three-factor BAS division (Carver \& White, 1994) is sound, others have suggested that BAS may only consist of two different factors (Caseras et al., 2003). If, however, the three-factor division of BAS is accurate, the failure to confirm this structure in the Muris et al. (2005) sample may be a result of an underdeveloped BAS in children. This speculation suggests that environmental factors which contribute to the development of the complete BAS may not emerge until later in adolescence.

In a study that specifically focused on BIS sensitivity, Field (2006) adapted the BIS subscale from the BIS/BAS Scales (Carver \& White, 1994) for use with children. In a validation attempt, a single factor representing BIS emerged, and it was highly correlated with its counterpart of the scale designed by Muris et al. (2005). In the next phase of the study, $n=60$ children participated in a task designed to measure attentional bias towards negative pictures of animals. It was hypothesized that when threatening information about an animal was presented, children's attention would be directed towards the picture of that animal, and would have quicker reaction times when a dot probe was present 
under that picture. Results of this phase showed that BIS sensitivity was a significant moderator of attentional bias in children. As BIS sensitivity increased, the attention toward the threatening animal increased as well.

The last phase of the study examined the relation between BIS sensitivity and the behavioural components of anxiety. It was hypothesized that BIS sensitivity would moderate the relation between threat information and behavioural avoidance (i.e., as BIS sensitivity increases, children will become more avoidant of animals for which threat information was received; conversely, as BIS sensitivity decreased, children will be less avoidant of the animals of which threat information was received). One hundred twentyseven children participated in this phase of the study. Overall, results showed that threat information about a novel animal was sufficient to elicit avoidance behaviour in children. Furthermore, it was found that BIS sensitivity tended to moderate this relation. As BIS sensitivity increased, so did the avoidance of animals where threat information was received. However, as BIS sensitivity increased, reaction times to approach the animals where positive information was received tended to decrease. Field (2006) believes that this finding goes against the prediction of BIS and BAS being orthogonal in nature. Original RST hypothesizes that sensitivity to reward is responsible for approach behaviours, irrespective of sensitivity to punishment. In contrast, children characterized with high BIS sensitivity in this study approached the positive animals quicker than those with low BIS sensitivity, suggesting that the BIS may play a role in approach behaviours as well.

In another recent study looking at BIS/BAS in childhood, Slobodskaya (2007) conducted a two-phase study that examined the relations between BIS/BAS sensitivity, 
the Big Five personality dimensions and adjustment in childhood. A shortened version of the Gray-Wilson Personality Questionnaire (Knyazev, Slobodskaya, Kharchenko, \& Wilson, 2004) was used to assess BIS/BAS sensitivity. Results indicated that BIS sensitivity was positively related to Neuroticism, and negatively related to Extraversion, Conscientiousness, and Openness. BAS sensitivity was positively related to Disagreeableness and negatively related to Conscientiousness. As well, BIS was linked to anxiety, low mood, and somatic complaints, whereas BAS was linked to behavioural problems.

Taken together, self-report measures of BIS/BAS sensitivity also appear to be related to a number of adverse outcomes. Combined with the findings of the parent-report studies, it appears that BIS sensitivity is consistently related to emotional problems in childhood, whereas the findings in regards to BAS sensitivity are mixed. Furthermore, the independence of functioning between the two systems has been questioned (e.g., Field, 2006, Blair et al., 2004), which lends further credibility to the predictions of the joint systems hypothesis (Corr, 2002).

Evidence for the joint subsystems hypothesis in childhood. An extensive review of the literature revealed only two studies where researchers directly assessed components of the joint systems hypothesis in samples of children. In the first study, Knyazev and Wilson (2004) explored relations between self-reported BIS/BAS sensitivity and behaviour problems in a sample of $n=768$ Russian adolescents. Individually, BIS sensitivity was related to emotional symptoms and BAS sensitivity predicted levels of conduct disorder. However, consistent with the joint systems hypothesis, BAS sensitivity moderated the relation between BIS sensitivity and emotional symptoms. That is, 
adolescents who were both high in BIS and low in BAS were at the greatest risk for emotional problems. Furthermore, BIS sensitivity also appeared to moderate the relation between BAS sensitivity and conduct problems. Adolescents with both high BAS and low BIS were the most at risk for conduct problems. Interestingly, these effects were strongest for males.

In the second study, Coplan et al. (2006) explored the socio-emotional functioning of children with different combinations of BIS and BAS sensitivities. Participants were $n=95$ children aged 6-14 years. It should be noted that study employed the original (adult) version of the BIS/BAS scales (Carver \& White, 1994) as opposed to an age-downward version. Children also self-reported symptoms of depression, social anxiety, positive and negative affect, and subjective well-being. Among the results, BIS was found to be significantly and positively correlated with depressive symptoms, negative affect, social anxiety, as well as negatively correlated with subjective wellbeing. Conversely, BAS was significantly and negatively correlated with depression, negative affect, and social anxiety. Children were then assigned to four groups based on all possible combinations of high and low (median splits) BIS and BAS sensitivity. Overall, children who were high on BIS and low on BAS seemed to fare the worst when compared to other groups. This group of high-BIS / low-BAS children reported the most depressive symptoms, negative affect, social anxiety, and the lowest positive affect and well-being.

Thus, there is at least some empirical evidence in support one of the predictions of the joint subsystems hypothesis. Two studies have reported an interaction between the two subsystems in the prediction of behavior problems under conditions of normal 
functioning. Although the relation between each individual subsystem and behavioural/emotional outcomes is informative, the influence of the other subsystem should also be taken into consideration. As most research is conducted on non-clinical populations, it is assumed that the BIS and BAS will both influence the outcomes associated with each. For extreme groups, the joint subsystems hypothesis predicts that the strongest system will assert dominance in behavioural control, regardless of the level of the other.

\section{The Present Study}

In summarizing the research examining the relation between BIS/BAS sensitivity and psychopathology in childhood and adolescence, BIS sensitivity consistently displays positive associations with depression, anxiety, threat perception, behavioural avoidance, and negative affect, and negative relations to positive affect and overall well-being. In contrast, BAS sensitivity displays less consistent results, with a few studies finding links with indices of externalizing disorders, and others reporting no significant associations

(Blair, 2003; Blair et al., 2004; Colder \& O'Connor, 2004; Coplan et al., 2006; Field, 2006; Muris et al., 2005; Slobodskaya, 2007). However, although the BAS appears to be less "influential" (in terms of linear associations) than the BIS in childhood, its potential role as a moderator in the links between BIS and indices of psychopathology has recently gained some support (Blair et al., 2004; Knyazev \& Wilson, 2004).

As such, the primary goal of the present study was to examine the linear and interactive associations between BIS, BAS, and indices of internalizing difficulties in childhood. To accomplish this goal, an unselected sample of elementary school-aged children completed self-report measures of BIS/BAS sensitivity, internalizing problems 
(i.e., anxiety, depression) and socio-emotional functioning (loneliness, self-perceptions). Parents also completed an assessment of child internalizing and externalizing problems. A number of hypotheses were generated in regards to the relation between BIS/BAS sensitivity and adverse outcomes in the sample. First, it was expected that BIS sensitivity would be positively related to measures of internalizing difficulties (i.e., childreported depression, social anxiety, and loneliness, parent-reported emotional problems), and negatively related to perceived social concept. Second, it was predicted that BAS sensitivity would be negatively related to depression, social anxiety, loneliness, and perceived social concept, and positively related to externalizing problems. Third, it was hypothesized that BAS sensitivity would moderate the relations between BIS sensitivity and internalizing difficulties. Specifically, based on the predictions of the joint subsystems hypothesis, it was expected that high BIS sensitivity combined with low BAS sensitivity will show the strongest relation with internalizing measures as compared to all other combinations of BIS/BAS. No gender differences are typically reported with regards to overall BIS/BAS sensitivity or its correlates (e.g., Carver \& White, 1994). As

such, no specific predictions regarding child gender were expected. However, if warranted, child gender would serve as a control variable during statistical analyses.

Methods

\section{Participants}

The participants for this study were $\mathrm{N}=396$ children (196 boys, 200 girls) ranging in age from 9-13 years $\left(M_{\mathrm{age}}=10.16, S D=.95\right)$. All children were in grades 4-6 and attending public elementary schools in and around Ottawa, Canada. Father ethnicity was $81 \%$ Caucasian, $6 \%$ Hispanic, $2 \%$ Asian, $1 \%$ Aboriginal, and $2 \%$ other. Mother 
ethnicity was $81 \%$ Caucasian, $6 \%$ Hispanic, $1 \%$ Asian, . $5 \%$ Black, and $3 \%$ Other. Socioeconomic status (measured by mother and father education) appeared to be varied across the sample; $3.5 \%$ of mothers and $5 \%$ of fathers had only elementary school education, $18 \%$ of mothers and $21 \%$ of fathers had only a high school education, $57 \%$ of mothers and $52 \%$ of fathers had completed college or university, and $13 \%$ of mothers and $13 \%$ of fathers had completed a graduate degree. School board policies did not allow for information about parent income and employment status to be collected.

Procedure

The data for this study was collected in two cohorts. Data from Cohort $1(n=221)$ was collected between January-June, 2008. Data from Cohort $2(n=175)$ was collected between January-June, 2010. After receiving approval from relevant school boards, principals of schools were contacted in the December prior to data collection and asked if they would be willing to participate in the study. In early January of both cohort years, parents from consenting schools were given the information package (see Appendix A) consisting of an information letter, consent form, and a short demographic questionnaire. In early February, all children who were given parental permission were brought into a separate area of their school (e.g., gymnasium, cafeteria, empty classroom, etc.) to participate in the first round of group testing. In this first round, children were administered a variety of measures, of which the BIS/BAS Scales were included. In March/April of both cohort years, children were again brought into a group testing session where they were administered a second battery of measures including measures of social anxiety, depression, loneliness, and perceived social concept (see below for complete description of measures), among others not relevant to this particular study. 
Children were debriefed and thanked for their time. Finally, towards the end of the school year, parents were sent an information package that included the parent-report conduct and emotional problems questionnaires.

\section{Measures}

BIS/BAS Sensitivity. Children completed the "age-downward" version of the BIS/BAS Scales (see Appendix B; Carver \& White, 1994) adapted by Muris et al. (2005). The 20 items are scored from 1 ("strongly disagree") to 4 ("strongly agree"). It should be noted that one item on the BIS subscale is reversed scored (i.e., "I do not become worried fearful or nervous, even when something bad happens to me.'). The BIS/BAS Scales have been shown to have both good validity and reliability in adult samples, and have been shown to demonstrate a four-factor solution: BIS, BAS Reward responsiveness, BAS Drive, and BAS Fun seeking (e.g., Carver \& White, 1994). However, Muris et al. (2005) recently found only a two-factor solution (i.e., BIS and BAS) and good psychometric properties for a child version of the BIS/BAS Scales. As such, in the current study a single factor for BAS was calculated. In the present sample, internal consistency for the BAS subscale was $\alpha=.68$, and $\alpha=.65$ for the BIS subscale.

Social anxiety. Children's social anxiety was assessed using the Social Anxiety Scale for Children Revised (SASCR; La Greca \& Stone, 1993 - see Appendix C). The measure consists of 22 items (including 4 filler items) which comprise three subscales: fear of negative evaluation (FNE, 8 items, e.g., "I'm afraid that other kids will not like me"), social avoidance and distress in new situations (SAD-New, 6 items, e.g., "I feel shy around kids I don't know"), and social avoidance and distress in general (SAD-General, four items, e.g., "I am quiet when I'm with a group of kids"). Each item is rated in terms 
of how true the item is on a 5-point Likert-type scale $(1=$ not at all, $5=$ all the time $)$. All three subscales on the SASC-R have shown to have both good internal consistency (La Greca \& Stone, 1993; Weeks, Coplan, \& Kingsbury, 2009) and validity (La Greca \& Stone, 1993). In the current study, a total social anxiety score was calculated (see Weeks et al., 2009), with an internal consistency of $\alpha=.91$.

Loneliness. Feelings of loneliness in the children were assessed using the Loneliness and Social Dissatisfaction measure (Asher, Hymel, \& Renshaw, 1984 - see Appendix E). This measure consists of 16 items (plus eight filler items) where children respond on a 5-point scale indicating how much each statement is true of themselves. Following procedures outlined in Asher et al. (1984), the 16 items were summed to create a total loneliness and social dissatisfaction score ranging from 16 (low loneliness) to 80 (high loneliness). Previous research has shown that all 16 items load on one single factor (Asher et al., 1984; Asher \& Wheeler, 1985). The Loneliness and Social Dissatisfaction measure has been shown to have excellent internal consistency (Goossens \& Beyers, 2002) and validity (Asher et al., 1984, Asher $\&$ Wheeler, 1985). In the current sample, this measure demonstrated an internal consistency of $\alpha=.93$.

Depression. Levels of depressive symptoms were assessed using the short version of the Child Depression Inventory (CDI; Kovacs, 1981- see Appendix D). The CDI is a 27-item self-report questionnaire that is widely used to assess symptoms of depression in childhood. In this study, the item regarding suicidal ideation was omitted for ethical reasons. Items scores are rated on a 3-point scale, and are summed to create a total depression score. The CDI is one of the most widely used measures of depressive symptoms in childhood, and has demonstrated both good internal consistency (Coplan et 
al., 2006) and validity (Finch, Saylor, \& Edwards, 1985). In the current sample, the CDI demonstrated an internal consistency of $\alpha=.80$.

Perceived social concept. Children completed the Self-Description

Questionnaire, (see Appendix F) a commonly used measure of self-concept in children (e.g., Hymel, Bowker, \& Woody, 1993; Marsh, 1983; 1985). Although the general measure consists of seven separate subscales, only one subscale was of interest in this study: social self-concept (10 items). Children responded on a 5-point likert scale $(1=$ false, $5=$ true). The SDQ has demonstrated good internal consistency (Hymel et al., 1993 ) and good validity (Marsh, 1983; 1985). In the current sample, this measure demonstrated an internal consistency rating of $\alpha=.91$.

Child socio-emotional adjustment. Parents $(\mathrm{n}=143)$ of a sub-sample of participants completed the 'Emotional Symptoms' and 'Conduct Problems' subscales of the Strengths and Difficulties Questionnaire (SDQ; Goodman, 1997 - see Appendix G) as a measure of both emotional and behavioural adjustment. These SDQ subscales consist of 10 items ( 5 per subscale) scored on a 3 -point Likert scale $(1=$ not true, $2=$ sometimes true, 3 = certainly true). The SDQ is widely used as a screening questionnaire of psychological adjustment of 4-17 year old children (Calam, Gregg, \& Goodman, 2005; Goodman, 2001; Goodman, Ford, Corbin, \& Meltzer, 2004). Internal consistency for the SDQ subscales for the current sample was as follows: $\alpha=.73$ for 'emotional symptoms' and $\alpha=.69$ for 'conduct problems'. As only a sub-sample of the parents of children completed and returned the SDQ $(n=143)$, the data was split into groups of those who completed and those who did not, to determine if any heterogeneity in the sample existed. Independent samples $t$-tests were conducted on the means of all demographic, dependent, 
and predictor variables to determine where (if any) differences may have existed. No significant mean differences were found between those parents who completed the SDQ compared to those who did not. Therefore, confidence can be taken from the notion that no selection biases were present in the completion of this measure.

\section{Results}

\section{Preliminary Analyses}

Data screening. A visual examination of scatter plots revealed that only a few outliers were present in the sample. Any case lying further than three standard deviations above the mean were considered outliers and were removed. All analyses were then run with the offending cases removed. As this did not significantly change any of the results, results are presented with all cases included. The assumptions of independence, homoscedasticity, order, and normality for all measures were all examined. From the examination of scatter plots (observed versus predicted values, normal probability plots, and residual plots), relations between variables appeared to be linear and normally distributed, with only slight deviations. Also, error terms appeared to be independent and display constant variance, again only with minor deviations. As a result, no data transformation procedures were performed.

Demographic variables. Correlations between demographic and predictor variables were examined to determine if any variables needed to be controlled for in the main analyses (see Table 1). Of note, gender was significantly and positively correlated with levels of BIS sensitivity. An independent samples $t$-test revealed that girls displayed significantly higher levels of BIS sensitivity as compared to boys $\left(M_{\text {boys }}=2.65, S D=.47\right.$; $\left.M_{\text {girls }}=2.82, S D=.44 ; t(362)=-3.46, p=.001\right)$. As a result, gender was used as a 
Approach, Avoidance, and Psychopathology 31

Table 1. Correlations between BIS, BAS and demographic variables.

\begin{tabular}{ccc}
\hline & BIS & BAS \\
\hline Gender & $.18^{* *}$ & .03 \\
Age & -.02 & $-.11^{*}$ \\
Mother Education & .08 & .04 \\
Father Education & .03 & -.01 \\
\hline & & $* * p=.001, * p<.05$
\end{tabular}


control variable in step 1 of the subsequent hierarchical regression analyses. Age was also found to be negatively correlated with levels of BAS sensitivity. However, when age entered into the regression equations, the pattern of results remained the same. Therefore, all results are shown without age acting as a control variable.

Intercorrelations among all study variables. A correlation matrix of bivariate correlations between all study variables is presented in Table 2. Among the results of interest, BIS was significantly and positively correlated with BAS, depression, anxiety, loneliness, parent-report emotional problems, and significantly and negatively correlated with perceived social concept and parent-report conduct problems. Interestingly, BAS was not significantly correlated with any of the outcome variables in the study. Outcome variables were also significantly intercorrelated (see Table 2). The relations demonstrated between study variables are all theoretically consistent (e.g., depression and anxiety, perceived social concept negatively associated with adverse outcomes, etc.), and fall in the expected directions. All descriptive statistics for study variables are displayed in Table 3.

\section{Hierarchical Regression Analyses}

Overview. The goal of these analyses was to determine the unique and interactive contributions of BIS and BAS sensitivity in the prediction of outcome variables. A series of regression analyses was performed following procedures outlined by Aiken and West (1991). Gender was first entered as a control variable in Step 1 of the model. In Step 2, both BIS and BAS were entered. Finally, the BIS x BAS interaction term was entered in Step 3. Separate equations were computed for each of the outcome variables. 
Table 2. Intercorrelations among all study variables.

\begin{tabular}{|c|c|c|c|c|c|c|c|c|}
\hline & 1 & 2 & 3 & 4 & 5 & 6 & 7 & 8 \\
\hline 1. BIS & - & $.14^{*}$ & $.16^{*}$ & $.41 * *$ & $.14^{*}$ & $-.18^{*}$ & .16 & $-.25^{*}$ \\
\hline 2. BAS & & - & .02 & .11 & .06 & -.05 & -.07 & .03 \\
\hline 3. Depression & & & - & $.59 * *$ & $.66^{* *}$ & $-.59 * *$ & $.26^{*}$ & .15 \\
\hline 4. Anxiety & & & & - & $.67^{* *}$ & $-.63 * *$ & $.25^{*}$ & -.02 \\
\hline 5. Loneliness & & & & & - & $-.82 * *$ & $.26^{*}$ & -.12 \\
\hline 6. Social concept & & & & & & - & $-.27 *$ & -.12 \\
\hline 7. Emotional & & & & & & & - & $.34 * *$ \\
\hline 8. Conduct & & & & & & & & - \\
\hline
\end{tabular}


Table 3. Descriptive statistics of study variables.

\begin{tabular}{lccccc}
\hline & Mean & SD & Range & Skew & Kurtosis \\
\hline BIS & 2.74 & .46 & $1-3.86$ & -.47 & .79 \\
BAS & 2.96 & .34 & $1.26-4$ & -.68 & 2.90 \\
Depression & 12.02 & 2.59 & $10-27$ & 1.95 & 5.37 \\
Anxiety & 41.64 & 12.78 & $18-86$ & .44 & .07 \\
Loneliness & 1.95 & .64 & $1-5$ & 1.23 & 2.36 \\
Self-concept & 32.96 & 7.26 & $9-45$ & -.76 & .40 \\
SDQ Emotional & 2.15 & 2.19 & $0-9$ & 1.08 & .57 \\
SDQ Conduct & 1.13 & 1.47 & $0-7$ & 1.58 & 2.15 \\
\hline
\end{tabular}


Complete results are displayed in Table 4 and Table 5.

\section{Child Self-report Measures}

Depression. At step 1 of the equation, gender did not significantly predict selfreport depressive symptoms. At step 2, while BAS sensitivity did not predict depressive symptoms, BIS sensitivity significantly and positively acted as a predictor. Lastly, at Step 3, the BIS x BAS interaction did not significantly predict depressive symptoms.

Anxiety. At step 1 of the equation, gender did not significantly predict self-report anxiety. At step 2, BAS sensitivity did not predict anxiety. BIS sensitivity, on the other hand, significantly and positively predicted anxiety. Lastly, at Step 3, the BIS x BAS interaction did not significantly predict anxiety.

Loneliness. At step 1 of the equation, gender was a significant predictor of selfreport loneliness. At step 2, BAS sensitivity did not predict loneliness. BIS sensitivity and gender, on the other hand, significantly and positively predicted loneliness. Lastly, at Step 3, the BIS x BAS interaction did not significantly predict self-report loneliness. Perceived social concept. At step 1 of the equation, gender did not significantly predict self-report perceived social concept. At step 2, BAS sensitivity did not predict perceived social concept. BIS sensitivity, on the other hand, significantly and negatively predicted perceived social concept. Lastly, at step 3, the BIS x BAS interaction did not significantly predict perceived social concept.

\section{Parent-report Measures}

Emotional problems. At step 1 of the equation, gender did not significantly predict parent-report emotional problems. At step 2, BAS sensitivity did not predict emotional problems. BIS sensitivity, on the other hand, significantly and positively 
Table 4. Summary of hierarchical regression analyses predicting internalizing outcomes from BIS and BAS sensitivity.

\begin{tabular}{|c|c|c|c|c|c|}
\hline Outcome & Predictor Variable & $\mathrm{R}^{2}$ & $\mathrm{~F}$ & $\Delta \mathrm{R}^{2}$ & $\beta$ \\
\hline \multirow[t]{7}{*}{ Depression } & Step 1 & .00 & .22 & & \\
\hline & Gender & & & & .03 \\
\hline & Step 2 & .03 & 2.74 & .02 & \\
\hline & BIS & & & & $.16^{* *}$ \\
\hline & BAS & & & & .00 \\
\hline & Step 3 & .03 & 2.21 & .00 & \\
\hline & BIS $x$ BAS & & & & .05 \\
\hline \multirow[t]{7}{*}{ Anxiety } & Step 1 & .00 & 1.42 & & \\
\hline & Gender & & & & .07 \\
\hline & Step 2 & .17 & 21.51 & .16 & \\
\hline & BIS & & & & $.40 * * *$ \\
\hline & BAS & & & & .05 \\
\hline & Step 3 & .17 & 16.09 & .00 & \\
\hline & BIS $x$ BAS & & & & .01 \\
\hline
\end{tabular}


Table 4 cont.

\begin{tabular}{|c|c|c|c|c|c|}
\hline Outcome & Predictor Variable & $\mathrm{R}^{2}$ & $\mathrm{~F}$ & $\Delta \mathrm{R}^{2}$ & $\beta$ \\
\hline \multirow[t]{7}{*}{ Loneliness } & Step 1 & .01 & 4.40 & & \\
\hline & Gender & & & & $-.12 *$ \\
\hline & Step 2 & .04 & 4.52 & .03 & \\
\hline & BIS & & & & $.16^{* *}$ \\
\hline & BAS & & & & .04 \\
\hline & Step 3 & .04 & 3.58 & .00 & \\
\hline & BIS $x$ BAS & & & & -.05 \\
\hline \multirow[t]{7}{*}{ Social concept } & Step 1 & .00 & 1.06 & & \\
\hline & Gender & & & & .06 \\
\hline & Step 2 & .04 & 4.46 & .04 & \\
\hline & BIS & & & & $-.19 * *$ \\
\hline & BAS & & & & -.03 \\
\hline & Step 3 & .05 & 4.09 & .01 & \\
\hline & BIS $\times$ BAS & & & & $.10+$ \\
\hline
\end{tabular}


Table 5. Summary of hierarchical regression analyses predicting parent-reported outcomes from BIS and BAS sensitivity.

\begin{tabular}{|c|c|c|c|c|c|}
\hline Outcome & Predictor Variable & $\mathrm{R}^{2}$ & $\mathrm{~F}$ & $\Delta \mathrm{R}^{2}$ & $\beta$ \\
\hline \multirow[t]{7}{*}{ Emotional Problems } & Step 1 & .00 & .22 & & \\
\hline & Gender & & & & -.04 \\
\hline & Step 2 & .04 & 1.70 & .04 & \\
\hline & BIS & & & & $.19 *$ \\
\hline & BAS & & & & -.09 \\
\hline & Step 3 & .04 & 1.29 & .00 & \\
\hline & BIS $x$ BAS & & & & -.03 \\
\hline \multirow[t]{7}{*}{ Conduct Problems } & Step 1 & .04 & 5.52 & & \\
\hline & Gender & & & & $-.20^{*}$ \\
\hline & Step 2 & .09 & 4.30 & .05 & \\
\hline & BIS & & & & $-.23 * *$ \\
\hline & BAS & & & & .07 \\
\hline & Step 3 & .09 & 3.20 & .00 & \\
\hline & BIS $x$ BAS & & & & .01 \\
\hline
\end{tabular}


predicted emotional problems. Lastly, at step 3, the BIS x BAS interaction did not significantly predict emotional problems.

Conduct problems. At step 1 of the equation, gender did not significantly predict parent-report conduct problems. At step 2, BAS sensitivity did not predict conduct problems. BIS sensitivity, on the other hand, significantly and negatively predicted conduct problems. Lastly, at step 3, the BIS x BAS interaction did not significantly predict conduct problems.

Age and Gender. As both age and gender were significantly related to predictor variables (i.e., age and BAS, gender and BIS), it was of interest to run the main regression analyses using each of these variables as a predictor, as well as the relevant interaction terms (i.e., gender x BIS, gender x BAS; age x BIS, age x BAS). However, no significant main effects or interactions were found.

\section{Discussion}

The purpose of this study was to explore links between childhood BIS and BAS and indices of self-reported internalizing difficulties (e.g., anxiety, depressive mood) and parent-reported emotional and conduct problems. In particular, drawing upon the conceptual framework of the joint subsystems hypothesis, interactions between BIS and BAS were also explored in the prediction of child socio-emotional functioning. It was hypothesized that BIS sensitivity would be related to higher levels of internalizing problems and that BAS sensitivity would be negatively related to internalizing outcomes, and positively related to conduct problems. As well, it was speculated that BAS sensitivity would moderate relations between BIS and internalizing outcomes. 
Overall, results indicated that BIS sensitivity was strongly associated with both child self-reports and parent-report of internalizing outcomes, and negatively related to conduct problems. BAS sensitivity, on the other hand, was not significantly associated with any of the outcome variables. Furthermore, no support was found for the joint subsystems hypothesis. Results did not indicate any significant interaction effects between BIS and BAS sensitivity in the prediction of outcome variables. These results are discussed in further detail below.

Implications of BIS in Childhood

Overall, results from the current study provided strong additional evidence of the potential importance of BIS reactivity in childhood. To begin with, BIS was found to be a significant predictor of social anxiety, consistent with previous research with children and adolescents (Blair, 2003; Blair et al., 2004; Colder \& O’Connor, 2004; Coplan et al., 2006; Field, 2006; Muris et al., 2005; Slobodskaya, 2007). Moreover, BIS sensitivity was also a predictor of depressive symptoms in the sample, consistent with findings from previous studies using children in this age group (Coplan et al., 2006; Muris et al., 2005). The current study also extended previous results by demonstrating associations between BIS sensitivity and both feelings of loneliness and lower perceived social concept. As well, BIS sensitivity was associated with parental ratings of internalizing problems and negatively related to parental reports of conduct problems.

BIS and internalizing problems. The relation between BIS sensitivity and internalizing problems can be explained using the framework of RST (Gray, 1987). As stated previously, the main function of the BIS is to suppress all types of behaviours, favour risk-aversion, and heighten attention towards potentially threatening stimuli. As 
BIS sensitivity represents an 'overactive' nervous system that is highly sensitive to punishing cues in the environment, the relations with anxiety make intuitive sense. As depression and anxiety are strongly related constructs, it also follows that a strong BIS can also be linked to feelings of depression. Clark and Watson (1991) argued that both anxiety and depression share the characteristic of high levels of negative affect. What differentiates the two constructs is that depression is uniquely characterized by low levels of positive affect. Although positive and negative affect were not directly addressed in this study, BIS has been previously shown to be related to negative affect, whereas BAS has been shown to be related to positive affect (Coplan et al., 2006).

McNaughton and Corr (2008) hypothesized that symptoms associated with anxiety-based psychopathology may be generated by either an accurate response to stimuli (e.g., a life-threatening situation), a maladaptive neural structure (e.g., hypersensitivity), or a combination of both. With regards to the findings in our study, an overactive BIS may be responsible for the elevated levels of anxiety-based internalizing difficulties seen in our sample. As the sample was an unselected group of children, there was no reason to suspect that an over-representative amount of life-threatening experiences would beset these children. While it is entirely possible that the elevated levels of depressive symptoms and anxiety in some of the children may be an accurate response to unmeasured stimuli, it is nevertheless interesting to suspect the BIS as the culprit. However, the 'direction of causality' problem will inevitably always arise in studies with a correlational design. Nevertheless, the implication of these findings when assuming that the BIS is involved in the development of these symptoms is that they may be in part generated by a maladaptive neurological system, rather than being purely 
environmentally shaped. For example, the septo-hippocampal system has been implicated as the center of the anxious response, as both anxiolytic drugs and hippocampal lesions lead to a decrease in behavioural inhibition in animal experiments (McNaughton \& Corr, 2008). As well, posterior cingulate cortex activation appears to be specifically involved in behavioural inhibition (Berger, Weikart, Bassett \& Orr, 1986). While it is beyond the scope of this study to scratch anything below the surface of neuroscientific speculation, it is nevertheless interesting to implicate neuroanatomical structures in the etiology of internalizing problems. A dampening of the sensitivity of the BIS may provide an explanation as to why pharmacological interventions are effective in treating both depressive and anxious symptoms.

BIS sensitivity was also found to be linked to loneliness and low perceived social concept. These findings may be explained by the notion that socially anxious children tend to report poor quality group interaction (e.g., Gazelle \& Spangler, 2007; Greco \& Morris, 2005; Weeks et al., 2009). Poor peer relations may in turn lead to peer rejection, or voluntary self-removal from the peer group at large. If children are experiencing high levels of social anxiety, it may be quite difficult to initiate contact with other peers, or maintain a dialogue. Field (2006) found that children high in BIS sensitivity paid more attention to threatening cues in the environment, relative to those low in BIS sensitivity, as well as showing increased levels of behavioural avoidance - both telltale signs of anxiety. To this end, socially anxious children may interpret ambiguous social cues as threatening, and subsequently avoid contact with peers. Nevertheless, a lack of peer interaction has been shown to be negatively related to socio-emotional adjustment in childhood (Rubin et al., 2009). For example, a lack of social interaction has been 
associated with immature play behaviour (Rubin \& Borwick, 1984) and decreased selfassessment of social cognitive abilities (Rubin, 1985). A study by Strauss, Forehand, Smith, and Frame (1986) found that socially withdrawn children reported lower levels of self-esteem, as well as greater depression and anxiety when compared to those who were not socially withdrawn. It is possible that the elevated levels of loneliness and low perceived social concept resulted from feelings of anxiety and depressive symptoms, as all of the outcome variables demonstrated high correlations with each other in our sample. While one can only speculate as to the direction of these relations, it is a unique finding to relate BIS sensitivity to difficulties other than depression and anxiety. BIS and externalizing problems. While it was expected that BAS sensitivity would be linked with conduct problems, the literature provides at least partial support for the BIS being responsible for a portion of behavioural issues. In early RST studies looking at relations with psychopathology, Quay (1997) suggested that an underactive BIS may be responsible for the hyperactive behaviours and tendencies exhibited by those afflicted with ADHD. An underactive BIS fails to provide cues that lead to an inhibition of behaviours after punishing stimuli have been presented, resulting in the inappropriate behaviours seen in those with ADHD. However, other work suggests that an overactive BAS may instead be responsible for the externalizing problems associated with ADHD rather than the BIS (Nigg, 2001). Furthermore, Mitchell and Nelson-Gray (2006) also found that BAS sensitivity was related to ADHD symptoms, while BIS sensitivity was not. The study by Mitchell and Nelson-Gray (2006) however used a sample of youngadults, rather than children. The results of the present study seem to suggest that the BIS may exert some influence on conduct problems - at least those assessed by parent-report. 
It has been theorized that high levels of reward sensitivity lead children to act out 'impulsively' (Nigg, 2001). Following the rationale of the separable subsystems hypothesis (Corr, 2001), high reward sensitivity would cancel out any inhibitory effects of the BIS, leading one to being unable to control their behaviours. However, our sample demonstrated that a lack of inhibition, rather than reward sensitivity was predictive of externalizing problems. This finding supports the theoretical stance taken by Quay (1997) implicating the BIS, rather than the BAS being responsible for ADHD symptoms. While ADHD symptomatology was not assessed in the current study, conduct problems are a hallmark of children diagnosed with ADHD (Buitelaar \& Medori, 2010). Furthermore, methylphenidate - a psychostimulant - has been shown to be an effective form of therapy for reducing behavioural manifestations associated with ADHD (Buitelaar \& Medori, 2010). It is thought that hyposensitive brain regions associated with impulse control are activated with the therapeutic use of psychostimulants, leading to increased impulse control, increased attention-span, and better familial and social interactions overall (Buitelaar \& Medori, 2010). While the findings of our study only demonstrate a relation between conduct problems and BIS sensitivity, they nevertheless provide at least some support for the 'lack of inhibition' hypotheses (Quay, 1997).

\section{Implications of BAS in Childhood}

In contrast to the results pertaining to BIS, BAS sensitivity was not associated with any outcomes variables in the current study. These findings run somewhat contrary to those of previous studies where BAS sensitivity has been shown to be negatively (albeit modestly) related to anxiety, depression, and negative affect (e.g., Coplan et al., 2006; Muris et al. 2005). However, previous results pertaining to the correlates of BAS in 
childhood have been somewhat inconsistent. The BAS however, has been consistently linked with many different personality characteristics in children. For example, Knyazev et al. (2004) found that BAS sensitivity was positively related to Disagreeableness and negatively related to Conscientiousness. As well, Muris et al. (2005) found that BAS was associated with Neuroticism, and Extraversion, but not emotional problems.

There are a number of possible explanations for the lack of associations between BAS and outcome variables found in the current study. To begin with, it is possible that the age-downward version of the BIS/BAS Scales (Carver \& White, 1994) does not adequately assess BAS sensitivity in this age group. Indeed, this measure appears to yield a differential factor structure for children than for adults. Carver and White (1994) found a four-factor solution for the $B I S / B A S$ Scales among adults (a single BIS scale, three scales for BAS). Muris et al. (2005), however, reported a two-factor solution in a sample of children, with a single factor for both BIS and BAS. Consistent with Muris et al. (2005), a preliminary factor analysis supported only a two-factor solution for this measure in our sample (BIS and BAS).

However, other studies using the age-downward version of this measure have found relations between BAS sensitivity and negative outcomes. Coplan and colleagues (2006) found that BAS sensitivity was significantly and negatively correlated with depression, negative affect, and social anxiety. Muris et al. (2005) found modest correlations between BAS and assessments of externalizing problems in a sample of children that matched the age range of the participants in this study. Therefore, while the validity of using this measure could be questioned, previous studies have demonstrated that the use of this measure is acceptable with this age group. 
It is also possible that the BAS exerts less influence on behaviour and outcomes than does the BIS. Unlike the BIS, research has been inconsistent with regards to the BAS and negative outcomes, with some studies finding relations (e.g., Coplan et al., 2006; Muris et al., 2005), and others finding a lack of influence (Bijttebier et al., 2009). McNaughton and Corr (2008) have stated that both systems do not exhibit an equal influence on behaviour. Instead, they argue that in approach/avoidance conflicts, both animals and humans will display a bias towards risk aversion as a protective mechanism. This notion would suggest that perhaps innate survival instincts are more powerful than pleasure-seeking behaviours, as staying alive is the absolute goal of all organisms. Drawing upon this thought process, it may be possible that the BIS is the dominant behavioural control system, with the BAS exhibiting only secondary influence, if any at all.

Alternatively, it has been suggested that the BAS may not be fully developed in childhood, and therefore less influential in the development of socio-emotional constructs (Coplan et al., 2006; Muris et al., 2005). In this regard, it is possible that the BAS is environmentally shaped with exposure to rewarding stimuli in the environment to which children of this age group have not yet been exposed (Muris et al., 2005). Knyazev et al. (2004) found that BAS sensitivity was the best predictor of substance abuse (alcohol, tobacco, and recreational drug use) in a sample of adolescents aged 14-25. It is highly unlikely that children of the same age as our sample have experimented with substance use at this age. As well, Voigt et al. (2010) found that the fun-seeking subscale of the Carver and White (1994) BIS/BAS Scales was related to increased risky sexual behaviours, and substance use in an undergraduate sample. It must be noted that no 
assumption is being made in regards to sex and substance use being solely responsible for the formation of the BAS. However, it is interesting to note the differential relations between BAS and outcomes as children become adolescents and young adults.

Finally, it is possible that BAS sensitivity is related to outcomes other than the ones measured in this study. For example, Blair (2003) found that BAS sensitivity positively correlated with parent-reported temperamental anger. Furthermore, Blair et al. (2004) found that BAS sensitivity was also correlated with temperamental anger and approach. The only study that found any relation between BAS and internalizing selfreport outcomes was that of Coplan et al. (2006), who reported that BAS was negatively correlated with depression, negative affect, and social anxiety. In this regard, BAS was predictive of positive, or rather, a lack of negative outcomes. In studies conducted with adults, an overactive BAS has been associated with manic symptoms of bipolar disorder, food cravings, psychopathy, and a wide range of different types of substance abuse (Bijttebier et al., 2009; Voigt et al., 2010). As mentioned previously, no studies have yet examined the associations between these constructs and BIS/BAS sensitivity in children (most likely due to both practical, and ethical reasons).

Perhaps most surprising was the fact that the BAS was not related to parentreported conduct problems. As mentioned previously, BIS sensitivity was negatively related to conduct problems, but BAS sensitivity was not. Since the relation between an overactive BAS and conduct problems was first conceptualized by Quay (1993), only a few studies have provided empirical support. For example, Knyazev and Wilson (2004) found that BAS sensitivity predicted levels of conduct disorder in a sample of Russian adolescents aged 11-17. In an unselected sample of children aged 8-12 years, Muris et al. 
(2005) found a modest correlation between BAS sensitivity and both child-report and parent-report conduct problems on the SDQ. The results from our study however, failed to replicate these findings with a characteristically similar sample. Our study only used a single measure of conduct problems (i.e., parent-report), which primarily assesses outbursts and aggression in children. However, externalizing problems involve a multitude of constructs other than parent-report aggression that could have been measured (e.g., impulsivity, attention span, etc.). A different pattern of results may have been discovered if a broader array of externalizing measures were used.

\section{Joint Subsystems Hypothesis}

Gray (1987) originally proposed that the BIS and BAS were independently functioning systems that have no influence on one another. From this perspective, responses to reward should be the same at all levels of BIS sensitivity, and responses to punishment should be the same at all levels of BAS sensitivity (Corr, 2001). According to Corr (2001), this view falls in line with the separable subsystems hypothesis. The joint subsystems hypothesis subsumes that reward response would be highest in people with high BAS and low BIS reactivity, whereas aversive response would be highest in people with high BIS and low BAS reactivity (Corr, 2001). Behavioural outcomes are thought to be influenced by both the BIS and BAS, with situational influences interacting with each other to produce output (e.g., a high-reward situation coupled with a moderate amount of risk would reduce the rewarding influence of the situation).

If the BIS and BAS were completely independent subsystems, one would not expect a correlation between the two sensitivity scores. However, consistent with both Coplan et al. (2006) and Muris et al. (2005), a modest but significant positive correlation 
was found between BIS and BAS sensitivity in the current sample. Muris et al. (2005) suggested that this correlation may simply be a result of a response bias that exists in children of this age group (i.e., the tendency to score consistently high or low on a battery of measures). As parent-reported BIS/BAS sensitivity was not assessed, it is not clear if the correlation between the two measures is indeed a case of a response bias in the present sample, or a more pervasive finding. Nevertheless, this finding goes against the original notion postulated by Gray (1987) which states that the BIS and BAS are completely orthogonal.

Notwithstanding, the results from the present study did not provide any support for the joint subsystems hypothesis. It was predicted that BAS would moderate relations between BIS sensitivity and outcome variables. Specifically, it was thought that high levels of BAS sensitivity would attenuate the relation between the BIS and internalizing outcomes (i.e., depression, anxiety, loneliness, and perceived social concept). However, no significant interaction effects were found between BIS and BAS in any of the hierarchical regression analyses.

Of course, it is difficult to make strong conclusions based on a lack of statistically significant findings. It is certainly possible that BIS and BAS do interact in the prediction of outcomes, but this effect was simply not detected in the current study. There are a number of possible reasons why this might have occurred (as discussed in a later section). Notwithstanding, our "lack of results" can also be tentatively viewed as support for the separable subsystems hypothesis, while exercising caution in not over-interpreting null results. Corr (2002) predicted that the effects of the separable subsystems hypothesis would be present under three circumstances: (1) when strong appetitive/aversive stimuli 
are used; (2) when people with extreme BIS/BAS sensitivity are tested; and (3) in experimental situations that do not contain mixed reward and punishment cues. Corr (2002) further asserted that the joint subsystems hypothesis, however, would apply during normal human experience, and all other situations not meeting the listed criteria. The unselected non-clinical sample in the current study did not match any of the criteria listed for the separable subsystems hypothesis, yet no BIS x BAS interaction was found. Instead, it appears that the BIS was a more highly influential system irrespective of the levels of BAS, even in those without extreme BIS/BAS sensitivity.

Drawing upon the previously mentioned notion about an underdeveloped BAS in childhood, it is possible that no interactive effects were found between the BIS and BAS due to the BAS not being well developed at this age. However, it may be likely that as the BAS forms throughout the course of development in childhood/adolescence, the effects of the joint subsystems hypothesis may become more prominent. In this regard, results from some other previous studies have found that BIS and BAS sensitivity do indeed interact to produce differential outcomes - and thus support the joint subsystems hypothesis. For example, Knyazev and Wilson (2004) examined the link between BIS/BAS sensitivity and behaviour problems in an adolescent sample (aged 11-17). It was found that the BAS moderated the relation between the BIS and emotional symptoms (i.e., adolescents who were both high in BIS and low in BAS were at the greatest risk for emotional problems). Furthermore, the BIS also moderated the relation between the BAS and conduct problems, with adolescents with both high BAS and low BIS at the most at risk for conduct problems. Using a highly similar sample age-wise, Coplan et al. (2006) found that children characterized as having low-BAS/high-BIS sensitivity exhibited the 
highest levels of depression, anxiety, negative affect, and the lowest levels of positive affect and well-being when compared to other BIS/BAS combinations. Finally, although not directly using the joint subsystems hypothesis as theoretical framework, Blair et al. (2004) found an interaction between BIS and BAS where high-BAS sensitivity 'cancelled-out' salivary cortisol changes attributed to high-BIS sensitivity. While these findings were on a pre-school aged sample (3-5 years), BIS/BAS sensitivity was assessed by parent-report. It is interesting to see how a differential assessment of BIS/BAS sensitivity (i.e., parent-report) leads to a pattern of results different from the current study. Whether or not children are misinterpreting the items on self-report assessments, or whether parents are inaccurately perceiving non existent constructs remains to be seen.

Overall, the lack of findings supporting the joint subsystems hypothesis in this study may also be attributed to the same issues raised when discussing the main effects of BIS/BAS sensitivity. BAS sensitivity on its own did not predict any of the outcome measures, so it is understandable that no interaction effects were found. However, a lack of a significant main effect does not necessarily imply that no significant interaction can be found. That being said, BIS sensitivity does appear to dominate in regards to the prediction of outcomes in this study.

\section{Limitations and Directions for Future Research}

The present study contributes to our knowledge of the etiology of internalizing difficulties in middle childhood, and may potentially help us further differentiate between seemingly related constructs (i.e., depression and anxiety). Examining the etiology of anxiety-based problems in childhood is important to understand how early emerging risk factors (i.e., personality traits) may contribute to more severe problems in adulthood. 
Furthermore, there is a gap in the literature pertaining to subclinical populations, as research traditionally focuses on internalizing difficulties once they have already emerged into a diagnosable disorder. Notwithstanding these points, there are some limitations that need to be considered in the interpretation of the results, which are discussed with an eye towards future directions.

Although it is redundant to continually mention the caveats associated with correlational designs, it is important to stress that causality can never be inferred from this type of analysis. For example, it cannot be assumed that high BIS sensitivity was in place before the development of anxiety and depression, and consequently leads to the development of these problems. It is entirely possible that the outcomes of interest existed first, and as a result, increased the sensitivity of the BIS. As well, the 'thirdvariable' problem always exists in the realm of explanatory possibilities - that is, there may be an as of yet unknown construct that is related to both the outcome measures and BIS/BAS sensitivity that explains the relations between the two.

A solution to these issues would be to employ a longitudinal design with multiple time-points of measurement. If BIS/BAS sensitivity and the outcomes were collected both at the start of the year, and again at the end, changes in these constructs could be assessed, and directionality could potentially be inferred. Even a short-term design like the one described above would be able to provide a richness that lacks from singular time-point data. At the time of writing, no studies with children on this topic have used a longitudinal design. A long-term longitudinal design would allow us to continually measure BIS/BAS sensitivity, and therefore be able to track the developmental course of these constructs. More specifically, the question of the development of the BAS and 
associated outcomes (e.g., substance use) can be investigated, as well as changes in the magnitude of the relations between BIS and emotional problems. It is not known whether the relations between the BIS and internalizing difficulties increases, or becomes attenuated with age.

As well, although the sample size was more than adequate with respect to providing statistical power, the homogeneity of the sample in regards to being middleclass and primarily Caucasian limited the generalizability of the findings to more diverse populations. For example, pressures associated with low-SES households may elicit different levels of all of the variables, and consequently potentially different results While high-SES has been related to school readiness and academic achievement, lowSES has been associated with an increase in both externalizing and internalizing outcomes in children (Leventhal \& Brooks-Gunn, 2000). It would also be interesting to explore these relations in more clinical samples (i.e., selected for anxiety, depression, ADHD, conduct disorder, etc.) to see how the pattern of results differs for an unselected sample.

For our primary analyses, self-reports of both BIS/BAS sensitivity, and all internalizing measures were used (i.e., depression, anxiety, loneliness, and perceived social concept). A number of issues arise with the use of self-report measures, such as response biases, shared-method variance problems, and social desirability effects to name a few. However, the use of parent-report emotional problems strengthens the findings regarding BIS and internalizing outcomes with a multi-method assessment. Future studies could benefit by using a continued multi-method approach by employing teacher reports, clinical assessments, and direct behavioural observation to complement self-reports. 
Furthermore, a multi-source assessment would allow for more complex, multivariate data analyses to be used.

It is also important to remember that the RST recently underwent a reformulation, with some fundamental changes made to the theorization of the BIS (Gray \& McNaughton, 2000). The original version of theory classified the BIS as the primary avoidance center in the brain. However, with the inclusion of the FFFS in the revision, the functions of the BIS changed. The differentiation between fear and anxiety are pointed out by McNaughton and Corr (2008). Fear typically results in fleeing behaviour, and can be related to as a form of panic. Anxiety, on the other hand, is best described as a feeling of wariness, or apprehension, but will not necessarily result in avoidance behaviours. Fear will direct an organism away from danger, and is insensitive to the effect of anxiolytic drugs. All of the behavioural correlates associated with anxiety, on the other hand, are sensitive to anxiolytic drugs (McNaughton \& Corr, 2008).

To date, the most reliable measure of BIS/BAS sensitivity (i.e., BIS/BAS Scales; Carver \& White, 1994) is based on the original theory. Recently, it has been argued that the BIS subscale of the BIS/BAS Scales (Carver \& White, 1994) actually contains items that assess both the FFFS and the reformulated BIS (Heym, Ferguson, \& Lawrence, 2008). In a current study using a clinical sample of anxious children, Vervoort et al. (2010) found that the BIS subscale consists of two factors (BIS-Anxiety, and FFFS-Fear). Overall, BIS scores were related to all types of anxiety, while BAS was not. Despite a factor-analysis confirming the presence of BIS-Anxiety and FFFS-Fear, only simple correlations between the subscales were presented. BIS-Anxiety scores were higher in the anxious group compared to healthy controls, and related to all types of anxiety. FFFS- 
Fear was also related to all types of anxiety, and most strongly correlated with Panic Disorder, and Social Phobia. While this study is the first of its kind that attempts to distinguish the BIS and FFFS, the scope of the findings are limited in nature, and further highlight the importance of the development of a new scale that assesses the unique functioning of the reformulated systems ${ }^{1}$.

As mentioned previously, research has demonstrated that BIS/BAS sensitivity is related to a host of psychopathological outcomes, such as substance abuse, bipolar disorder, symptoms of anorexia nervosa, and ADHD (Bijttebier et al., 2009). Although some of these subjects may not be entirely appropriate to study in children as young as the present sample (e.g., alcohol, tobacco, and recreational drug abuse), future studies could diversify the variables of interest in younger populations to further explore relations between the BIS/BAS subsystems and other outcomes. Lastly, it would be interesting to examine the overall developmental pattern of the BIS and BAS themselves, rather than the development of the outcomes associated with these systems. For example, temperamental characteristics in infancy, parenting styles, peer-interactions, may all contribute to weakening or strengthening of the sensitivity of the BIS/BAS subsystems.

\section{Summary and Conclusions}

The purpose of this study was to examine the associations between the BIS, BAS, and indices of internalizing and externalizing difficulties in childhood. Overall, results indicated that the BIS was associated with increased levels of depressive symptoms, anxiety, loneliness, and decreased levels of perceived social concept and parent-report conduct disorder. The BAS, however, was not associated with any of the outcomes. As

\footnotetext{
${ }^{1}$ For the sake of interest, the BIS subscale was divided into the Vervoort et al. (2010) formulation, despite only having one clear factor for BIS. All analyses were re-run, including FFFS-Fear as a predictor variable,
} 
well, no interactions between BIS and BAS were found to significantly predict these outcomes, and thus the present study failed to find support for the joint subsystems hypothesis.

The findings of this study shed further light on the development of internalizing difficulties in childhood. Understanding that innate mechanisms such as the BIS/BAS subsystems have an impact on psychopathological symptoms may help us focus our research on lessening the severity of the sensitivity of these biological systems. Whether pharmacological or cognitive-behavioural therapies would be effective in reducing subsystem sensitivity is yet to be known. Nevertheless, identifying the non-environmental contribution to problems such as depression and anxiety allows us to add to our understanding of the developmental course of these constructs. 


\section{References}

Asher, S. R., Hymel, S., \& Renshaw, P. D. (1984). Loneliness in children. Child Development, 55(4), 1456-1464.

Asher, S. R., \& Wheeler, V. A. (1985). Children's loneliness: A comparison of rejected and neglected peer status. Journal of Consulting and Clinical Psychology, 53(4), 500-505.

Ball, S. A., \& Zuckerman, M. (1990). Sensation seeking, Eysenck's personality dimensions and reinforcement sensitivity in concept formation. Personality and Individual Differences, 11(4), 343-353.

Bandler, R., Keay, K. A., Floyd, N., \& Price, J. (2000). Central circuits mediating patterned autonomic activity during active vs. passive emotional coping. Brain Research Bulletin, 53(1), 95-104.

Bandler, R. (1982). Neural control of aggressive behaviour. Trends in Neurosciences, 5(11), 390-394.

Berger, T. W., Weikart, C. L., Bassett, J. L., \& Orr, W. B. (1986). Lesions of the retrosplenial cortex produce deficits in reversal learning of the rabbit nictitating membrane response: Implications for potential interactions between hippocampal and cerebellar brain systems. Behavioral Neuroscience, 100(6), 802-809.

Beevers, C. G., \& Meyer, B. (2002). Lack of positive experiences and positive expectancies mediate the relationship between BAS responsiveness and depression. Cognition \& Emotion, 16(4), 549-564.

Bijtebbier, P., Beck, I., Claes, L., \& Vandereycken, W. (2009). Gray's reinforcement sensitivity theory as a framework for research on personality-psychopathology associations. Clinical Psychology Review, 29(5), 421-430.

Blair, C. (2003). Behavioral inhibition and behavioral activation in young children: Relations with self-regulation and adaptation to preschool in children attending head start. Developmental Psychobiology, 42(3), 301-311. 
Blair, C., Peters, R., \& Granger, D. (2004). Physiological and neuropsychological correlates of Approach/Withdrawal tendencies in preschool: Further examination of the behavioral inhibition System/Behavioral activation system scales for young children. Developmental Psychobiology, 45(3), 113-124.

Brown, T. A., Chorpita, B. F., \& Barlow, D. H. (1998). Structural relationships among dimensions of the $D S M-I V$ anxiety and mood disorders and dimensions of negative affect, positive affect, and autonomic arousal. Journal of Abnormal Psychology, 107(2), 179-192.

Buitelaar, J., \& Medori, R. (2010). Treating attention-deficit/hyperactivity disorder beyond symptom control alone in children and adolescents: A review of the potential benefits of long-acting stimulants. European Child \& Adolescent Psychiatry, 19(4), 325-340.

Calam, R., Gregg, L., \& Goodman, R. (2005). Psychosomatic Medicine, 67, 10-110.

Carver, C. S., \& White, T. L. (1994). Behavioral inhibition, behavioral activation, and affective responses to impending reward and punishment: The BIS/BAS scales. Journal of Personality and Social Psychology, 67(2), 319-333.

Carver, C. S. (2004). Negative affects deriving from the behavioral approach system. Emotion, 4(1), 3-22.

Caseras, X., Ávila, C., \& Torrubia, R. (2003). The measurement of individual differences in behavioural inhibition and behavioural activation systems: A comparison of personality scales. Personality and Individual Differences, 34(6), 999-1013

Clark, L. A., \& Watson, D. (1991). Tripartite model of anxiety and depression: Psychometric evidence and taxonomic implications. Journal of Abnormal Psychology. Special Issue: Diagnoses, Dimensions, and DSM-IV: the Science of Classification, 100(3), 316-336.

Colder, C. R., \& O'Connor, R. M. (2004). Gray's reinforcement sensitivity model and 
child psychopathology: Laboratory and questionnaire assessment of the BAS and BIS. Journal of Abnormal Child Psychology: An Official Publication of the International Society for Research in Child and Adolescent Psychopathology, 32(4), 435-451.

Coplan, R. J., Wilson, J., Frohlick, S. L., \& Zelenski, J. (2006). A person-oriented analysis of behavioral inhibition and behavioral activation in children. Personality and Individual Differences, 41(5), 917-927.

Corr, P. J. (2001). Testing problems in J. A. gray's personality theory: A commentary on Matthews and Gilliland (1999). Personality and Individual Differences, 30(2), 333-352.

Corr, P. J. (2002). J. A. gray's reinforcement sensitivity theory: Tests of the joint subsystems hypothesis of anxiety and impulsivity. Personality and Individual Differences, 33(4), 511-532.

Corr, P. J., \& McNaughton, N. (2008). Reinforcement Sensitivity Theory and personality. In P. J. Corr (Ed.), The Reinforcement Sensitivity Theory of Personality (pp. 155-187). Cambridge: Cambridge University Press

Costa, P. T., Jr., \& McCrae, R. R. (1985). The NEO personality inventory manual. Odessa, FL: Psychological Assessment Resources.

Deakin, J. W., \& Graeff, F. G. (1991). 5-HT and mechanisms of defence. Journal of Psychopharmacology, 5(4), 305-315.

Depue, R. A., Krauss, S. P., \& Spoont, M. R. (1987). A two-dimensional threshold model of seasonal bipolar affective disorder. In D. Magnusson, \& A. Öhman (Eds.), Psychopathology: An interactional perspective. (pp. 95-123). San Diego, CA, US: Academic Press.

DiNardo, P. A., \& Barlow, D. H. (1990). Syndrome and symptom co-occurrence in the 
Approach, Avoidance, and Psychopathology 60

anxiety disorders. In J. D. Maser, \& C. R. Cloninger (Eds.), Comorbidity of mood and anxiety disorders. (pp. 205-230). Washington, DC, US: American Psychiatric Association.

Eysenck, H. J. (1957). The dynamics of anxiety and hysteria; an experimental application of modern learning theory to psychiatry. Oxford, England: Frederick A. Praeger.

Eysenck, H. J. (1967). The biological basis of personality. Thomas: Spring-field, Ill. Finch, A. J., Saylor, C. F., \& Edwards, G. L. (1985). Children's depression inventory: Sex and grade norms for normal children. Journal of Consulting and Clinical Psychology, 53(3), 424-425.

Field, A. P. (2006). The behavioral inhibition system and the verbal information pathway to children's fears. Journal of Abnormal Psychology, 115(4), 742-752.

Fowles, D. C. (1980). The three arousal model: Implications of gray's two-factor learning theory for heart rate, electrodermal activity, and psychopathy. Psychophysiology, 17(2), 87-104.

Fowles, D. C. (1988). Psychophysiology and psychopathology: A motivational approach. Psychophysiology, 25(4), 373-391.

Goodman, R. (1997). The Strengths and Difficulties Questionnaire: A research note. Journal of Child Psychology, Psychiatry, and Allied Disciplines, 38(5), 581-586.

Goodman, R. (2001). Psychometric properties of the Strengths and Difficulties Questionnaire (SDQ). Journal of the American Academy of Child and Adolescent Psychiatry, 40, 1337-1345.

Goodman, R., Ford, T., Corbin, T., \& Meltzer, H. (2004). Using the Strengths and Difficulties Questionnaire (SDQ) multi-format algorithm to screen looked-after children for psychiatric disorders. European Child and Adolescent Psychiatry, 13(1), ii25-ii31.

Goossens, L., \& Beyers, W. (2002). Comparing measures of childhood loneliness: 
Internal consistency and confirmatory factor analysis. Journal of Clinical Child and Adolescent Psychology, 31(2), 252-262.

Gray, J. A. (1970). The psychophysiological basis of introversion-extraversion. Behaviour Research and Therapy, 8(3), 249-266.

Gray, J. A. (1982). The neuropsychology of anxiety: An enquiry into the functions of the septo-hippocampal system. New York, NY, US: Clarendon Press/Oxford University Press.

Gray, J. A. (1987). The psychology of fear and stress (2nd ed.). New York, NY, US: Cambridge University Press.

Gray, J. A., \& McNaughton, N. (2000). The neuropsychology of anxiety: An inquiry into the functions of the septo-hippocampal system. Oxford: Oxford University Press.

Greco, L. A., \& Morris, T. L. (2005). Factors including the link between social anxiety and peer acceptance: Contributions of social skills and close friendships during middle childhood. Behavior Therapy, 36, 197-205.

Heym, N., Ferguson, E., \& Lawrence, C. (2008). An evaluation of the relationship between gray's revised RST and Eysenck's pen: Distinguishing BIS and FFFS in carver and white's BIS/BAS scales. Personality and Individual Differences, 45(8), 709-715.

Hull, C. L. (1952). A behavior system; an introduction to behavior theory concerning the individual organism. New Haven, CT, US: Yale University Press.

Hymel, S., Bowker, A., \& Woody, E. (1993). Aggressive versus withdrawn unpopular children: Variations in peer and self-perceptions in multiple domains. Child Development, 64(3), 879-896.

Johnson, S. L., Turner, R. J., \& Iwata, N. (2003). BIS/BAS levels and psychiatric 
disorder: An epidemiological study. Journal of Psychopathology and Behavioral Assessment, 25(1), 25-36.

Jorm, A. F., Christensen, H., Henderson, A. S., Jacomb, P. A., Korten, A. E., \& Rodgers, B. (1999). Using the BIS/BAS scales to measure behavioural inhibition and behavioural activation: Factor structure, validity and norms in a large community sample. Personality and Individual Differences, 26(1), 49-58.

Kimbrel, N. A., Nelson-Gray, R. O., \& Mitchell, J. T. (2007). Reinforcement sensitivity and maternal style as predictors of psychopathology. Personality and Individual Differences, 42(6), 1139-1149.

Knyazev, G. G., Slobodskaya, H. R., Kharchenko, I. I., \& Wilson, G. D. (2004).

Personality and substance use in Russian youths: The predictive and moderating role of behavioural activation and gender. Personality and Individual Differences, $37(4), 827-843$.

Knyazev, G. G., \& Wilson, G. D. (2004). The role of personality in the co-occurrence of emotional and conduct problems in adolescents: A confirmation of corr's "joint subsystems" hypothesis. Personality and Individual Differences, 37(1), 43-63.

Kovacs, M. (1981). Rating scales to assess depression in school-aged children. Acta Paedopsychiatrica: International Journal of Child \& Adolescent Psychiatry, $46(5-6), 305-315$.

La Greca, A. M., \& Stone, W. L. (1993). Social anxiety scale for Children-Revised: Factor structure and concurrent validity. Journal of Clinical Child Psychology, $22(1), 17-27$.

LeDoux, J.E. (1994). Emotion, memory and the brain. Scientific American, 270, 50-59.

Leventhal, T., \& Brooks-Gunn, J. (2000). The neighborhoods they live in: The effects of neighborhood residence on child and adolescent outcomes. Psychological Bulletin, 126(2), 309-337.

Marsh, H. W., Smith, I. D., \& Barnes, J. (1983). Multitrait-multimethod analyses of the 
Self Description Questionnaire: Student-teacher agreement on multidimensional ratings of student self-concept. American Educational Research Journal, 20, 333357.

Marsh, H. W., Smith, I. D., \& Barnes, J. (1985). Multidimensional self-concepts Relations with sex and academic achievement. Journal of Educational Psychology, 77, 581-596.

McNaughton, N., \& Corr, P. J. (2008). The neuropsychology of fear and anxiety: A foundation for reinforcement sensitivity theory. In P. J. Corr (Ed.), The reinforcement sensitivity theory of personality. (pp. 44-94). New York, NY, US: Cambridge University Press.

Mitchell, J. T. \& Nelson-Gray, R. O. (2006). Attention-deficit /hyperactivity disorder symptoms in adults: Relationship to Gray's behavioral approach system. Personality and Individual Differences, 40, 749-760

Muris, P., Meesters, C., de Kanter, E., \& Timmerman, P. E. (2005). Behavioural inhibition and behavioural activation system scales for children: Relationships with eysenck's personality traits and psychopathological symptoms. Personality and Individual Differences, 38(4), 831-841.

Nigg, J. T. (2001). Is ADHD a disinhibitory disorder? Psychological Bulletin, 127(5), 571-598.

Patterson, C. M., Kosson, D. S., \& Newman, J. P. (1987). Reaction to punishment, reflectivity, and passive avoidance learning in extraverts. Journal of Personality and Social Psychology, 52(3), 565-575.

Pickering, A. D., \& Smillie, L. D. (2008). The behavioural activation system: Challenges and opportunities. In P. J. Corr (Ed.), The reinforcement sensitivity theory of personality. (pp. 120-154). New York, NY, US: Cambridge University Press.

Quay, H. C. (1993). The psychobiology of undersocialized aggressive conduct 
disorder: A theoretical perspective. Development and Psychopathology. Special Issue: Toward a Developmental Perspective on Conduct Disorder, 5(1-2), 165180.

Quay, H. C. (1997). Inhibition and attention deficit hyperactivity disorder. Journal of Abnormal Child Psychology: An Official Publication of the International Society for Research in Child and Adolescent Psychopathology, 25(1), 7-13.

Ross, S. R., Millis, S. R., Bonebright, T. L., \& Bailley, S. E. (2002). Confirmatory factor analysis of the behavioral inhibition and activation scales. Personality and Individual Differences, 33(6), 861-865.

Rubin, K.H. (1985). Socially withdrawn children: An "at risk" population?

In B. Schneider, K. H. Rubin, \& J. Ledingham (Eds.), Children's peer relations: Issues in assessment and intervention (pp. 125-139). New York: SpringerVerlag.

Rubin, K.H., Coplan, R.J., \& Bowker, J. (2009). Social withdrawal in childhood. Annual Review of Psychology, 60, 11.1-11.31.

Rubin, K.H. \& Borwick, D. (1984). Communicative skills and sociability. In H.E. Sypher \& J.L. Applegate (Eds.), Communication by children and adults: Social cognitive and strategic processes (pp. 152-170). Beverly Hills, Ca.: Sage Publications.

Sanderson, W. C., DiNardo, P. A., Rapee, R. M., \& Barlow, D. H. (1990). Syndrome comorbidity in patients diagnosed with a $D S M-I I I-R$ anxiety disorder. Journal of Abnormal Psychology, 99(3), 308-312.

Schultz, W. (1998). Predictive reward signal of dopamine neurons. Journal of Neurophysiology, 80(1), 1-27.

Slobodskaya, H. R. (2007). The associations among the big five, behavioural inhibition and behavioural approach systems and child and adolescent adjustment in russia. Personality and Individual Differences, 43(4), 913-924. 
Strauss, C.C., Forehand, R., Smith, K., \& Frame, C.L. (1986). The association between social withdrawal and internalizing problems of children. Journal of Abnormal Child Psychology, 14(4), 525-535.

Torrubia, R., \& Tobeña, A. (1984). A scale for the assessment of "susceptibility to punishment" as a measure of anxiety: Preliminary results. Personality and Individual Differences, 5(3), 371-375.

Torrubia, R., Ávila, C., Moltó, J., \& Caseras, X. (2001). The sensitivity to punishment and sensitivity to reward questionnaire (SPSRQ) as a measure of gray's anxiety and impulsivity dimensions. Personality and Individual Differences, 31(6), 837862 .

Torrubia, R., Ávila, C., \& Caseras, X. (2008). Reinforcement sensitivity scales. In P. J. Corr (Ed.), The reinforcement sensitivity theory of personality. (pp. 188-227). New York, NY, US: Cambridge University Press.

Vervoort, L., Wolters, L. H., Hogendoorn, S. M., de Haan, E., Boer, F., \& Prins, P. J. M. (2010). Sensitivity of Gray's behavioral inhibition system in clinically anxious and non-anxious children and adolescents. Personality and Individual Differences, 48(5), 629-633.

Voigt, D. C., Dillard, J. P., Braddock, K. H., Anderson, J. W., Sopory, P., \& Stephenson, M. T. (2009). Carver and white's (1994) BIS/BAS scales and their relationship to risky health behaviours. Personality and Individual Differences, 47(2), 89-93.

Weeks, M., Coplan, R. J., \& Kingsbury, A. (2009). The correlates and consequences of early appearing social anxiety in young children. Journal of Anxiety Disorders, 23(7), 965-972.

Wilson, G. D., Barrett, P. T., \& Gray, J. A. (1989). Human reactions to reward and punishment: A questionnaire examination of gray's personality theory. British Journal of Psychology, 80(4), 509-515. 
Approach, Avoidance, and Psychopathology 66

Zinbarg, R. E., Barlow, D. H., Liebowitz, M., \& Street, L. (1994). The DSM-IV field trial for mixed anxiety-depression. The American Journal of Psychiatry, 151(8), 11531162.

Zinbarg, R. E., \& Barlow, D. H. (1996). Structure of anxiety and the anxiety disorders: A hierarchical model. Journal of Abnormal Psychology, 105(2), 181-193.

Zinbarg, R. E., \& Yoon, K. L. (2008). RST and clinical disorders: Anxiety and depression. In P. J. Corr (Ed.), The reinforcement sensitivity theory of personality. (pp. 360-397). New York, NY, US: Cambridge University Press. 
Appendix A - Parental Information Package

\section{Dear Parent,}

\section{Child Social Activities Study Carleton University}

I am writing to ask your permission for your child to participate in a research study that is being conducted at your child's school. We are trying to learn more about the impact of children's social activities both in and outside of school. Learning to get along well with others is a major task of childhood. Some children are more sociable and outgoing, and enjoy meeting and interacting with larger groups of other children. Others are more shy and cautious, take longer to "warm-up" to social situations, and may feel more comfortable in smaller groups or one-on-one with a close friend. Some children are quite content to spend more time in quiet activities by themselves.

In this study, we are exploring some of the reasons why children may spend different amounts of time in social and solitary activities. In particular, we are interested in some of the factors that might influence children's feelings about their friends and themselves. This type of research is important because it will help us understand differences in children's social solitary activities. For example, in some cases, spending too much time alone can sometimes cause problems at school and with friends. Here is a more detailed description of what this project will involve (if you choose to participate):

Parents: Parents are being asked to complete some short questionnaires. The first concerns background information that will be used only to characterize this sample. Other questionnaires ask parents to describe themselves or their children. The first of these questionnaires are attached for your inspection. If you agree to participate in this study please complete the attached questionnaires and return them to your child's teacher along with the signed consent form (sealed in the envelope provided). Additional questionnaire packets may be sent home for you to complete later in the year. You are free to not answer any questions that you choose to omit.

Children: Children will be asked to participate in two group interviews (one in March, the other in May), consisting of several short questionnaires. Each session should take about 30 minutes. Some of the questionnaire items have to do with children's attitudes toward spending time alone, and how often they engage in a variety of activities by themselves. Other items concern how comfortable or anxious children may feel when they interact with others, and how they feel about their friends at school.

Observations: In March/April, a trained research assistant will also unobtrusively observe "goings-on" in the playground at recess and lunch. For example, she will record the frequency with which children are playing with others, interacting with the teacher, or playing alone. Observers will not interact directly with the children in the classroom. Please also note that observations will only be conducted for children who have received parental consent to participate in this study. 
These questionnaires will be done in groups, during a time period selected to minimize the disruption of any scheduled activities. Questions will be read aloud to the group, and children will be given time after each question. Children will be able to ask a research assistant for help if they have trouble understanding any of the questions. Also, your child will be reminded that they do not have to answer any questions they don't want to, and of course, they are free to stop participating at any time.

The information collected in this study is strictly confidential and will be made available only to researchers associated with this project. All questionnaires will be used only to gather information for data analysis, and individual questionnaire feedback will not be made available. This study has been approved by the Upper Canada District School Board, the Principal of your child's school, well as the Carleton University Ethics Committee for Psychological Research. If you have any questions related to this study and/or concerns about your child as a result of participation in this study, please feel free to contact me directly at 520-2600, ext. 8691 (or via e-mail at: robert_coplan@carleton.ca). Should you have any ethical concerns about this study, please contact Dr. A. Parush (Chair, Carleton University Ethics Committee for Psychological Research, 520-2600, ext. 6026) or Dr. A. Bowker (Chair, Dept. of Psychology, 520-2600, ext. 2648). If you would like to learn more about children's friendships and social adjustment at school, there are numerous websites on the topic (e.g., http://www.cfw.tufts.edu/) and books for parents (e.g., The Friendship Factor: Helping our Children Navigate Their Social World, by K. Rubin, NY: Viking Penguin).

Sincerely,

Robert Coplan, Ph.D.

Professor, Department of Psychology

Carleton University 


\section{Child Social Activities Study: Consent Form}

The information collected for this project is confidential and protected under the Municipal Freedom of Information and Privacy Act, 1989.

Date:

(name of child - please print)

(name of parent or guardian - please print

Child's Age (in years)

Child's birth date

Child's gender

Month Day Year

Please check one:

I give my permission for my child and I to participate in the Child Social Activities Study.

I do not give my permission for my child and I to participate in the Child Social Activities Study.

(signature of parent or guardian)

Please keep the letter (first page) and return the signed consent form and the completed questionnaire to your child's teacher sealed in the enclosed envelope. Please return the consent form as soon as possible even if you are not going to be participating in the study.

If you would like to receive a summary of the findings from this study please indicate an e-mail address or a mailing address in which we can send the results: 


\section{BACKGROUND INFORMATION}

\section{Child's}

Name

Birthdate

month

day

year

Boy

Girl

Grade

mother's formal education completed (check one):

elementary school

high school diploma or equivalent

community college or equivalent

university degree

graduate school degree

mother's ethnic group:

(optional)

father's formal education completed (check one):

elementary school

high school diploma or equivalent

community college or equivalent

university degree

graduate school degree
Child's Age (in years) 
Appendix B - BIS/BAS Scales

\section{How I Feel When Things Happen to Me}

The next questions ask you about your feelings. Circle the answer for each question that best describes you!

$$
(1 \text { - never, } 2 \text { - almost never, 3-sometimes, 4-always })^{2}
$$

1. I usually get very tense when I think something unpleasant is going to happen

2. I feel excited and full of energy when I get something that I want

3. When I want something, I usually go all the way to get it

4. I often do things for no other reason than that they might be fun

5. I worry about making mistakes

6. When I am doing well at something, I like to keep doing this

7. I do everything to get the things that I want

8. I have a great need for excitement and new sensations

9. I am hurt when people scold me or tell me that I do something wrong

10. I get thrilled when good things happen to me

11. When I see a chance to get something that I want, I go for it right away

12. I am always willing to try something new, when I think it will be fun

13. I feel pretty upset when I think that someone is angry with me

14. I do not become fearful or nervous, even when something bad happens to me*

15. I get very excited when I would win a contest

16. Nobody can stop me when I want something

17. I often do things on the spur of the moment

18. I feel worried when I think I have done poorly at something

19. I get really excited when I see an opportunity to get something I like

20. I am very fearful compared to my friends

\footnotetext{
${ }^{2}$ Answer boxes omitted to fit on page
} 
Appendix C - Social Anxiety Scale for Children

How I Feel Around Others

\begin{tabular}{|c|c|c|c|c|c|}
\hline 1. I worry about being teased. & $\begin{array}{c}1 \\
\text { Not } \\
\text { at } \\
\text { all }\end{array}$ & $\begin{array}{c}2 \\
\text { Hardly } \\
\text { ever }\end{array}$ & $\begin{array}{c}3 \\
\text { Sometimes }\end{array}$ & $\begin{array}{c}4 \\
\text { Most } \\
\text { of } \\
\text { the } \\
\text { time }\end{array}$ & $\begin{array}{c}5 \\
\text { All of } \\
\text { the } \\
\text { time }\end{array}$ \\
\hline $\begin{array}{l}\text { 2. I worry about what other kids think of } \\
\text { me. }\end{array}$ & $\begin{array}{c}1 \\
\text { Not } \\
\text { at } \\
\text { all }\end{array}$ & $\begin{array}{c}2 \\
\text { Hardly } \\
\text { ever }\end{array}$ & $\begin{array}{c}3 \\
\text { Sometimes }\end{array}$ & $\begin{array}{c}4 \\
\text { Most } \\
\text { of } \\
\text { the } \\
\text { time }\end{array}$ & $\begin{array}{c}5 \\
\text { All of } \\
\text { the } \\
\text { time }\end{array}$ \\
\hline $\begin{array}{l}\text { 3. I'm afraid that other kids will not like } \\
\text { me. }\end{array}$ & $\begin{array}{c}1 \\
\text { Not } \\
\text { at } \\
\text { all }\end{array}$ & $\begin{array}{c}2 \\
\text { Hardly } \\
\text { ever }\end{array}$ & $\begin{array}{c}3 \\
\text { Sometimes }\end{array}$ & $\begin{array}{c}4 \\
\text { Most } \\
\text { of } \\
\text { the } \\
\text { time }\end{array}$ & $\begin{array}{c}5 \\
\text { All of } \\
\text { the } \\
\text { time }\end{array}$ \\
\hline $\begin{array}{l}\text { 4. I worry about what other children say } \\
\text { about me. }\end{array}$ & $\begin{array}{c}1 \\
\text { Not } \\
\text { at } \\
\text { all }\end{array}$ & $\begin{array}{c}2 \\
\text { Hardly } \\
\text { ever }\end{array}$ & $\begin{array}{c}3 \\
\text { Sometimes }\end{array}$ & $\begin{array}{c}4 \\
\text { Most } \\
\text { of } \\
\text { the } \\
\text { time }\end{array}$ & $\begin{array}{c}5 \\
\text { All of } \\
\text { the } \\
\text { time }\end{array}$ \\
\hline 5. I feel that kids are making fun of me. & $\begin{array}{c}1 \\
\text { Not } \\
\text { at } \\
\text { all }\end{array}$ & $\begin{array}{c}2 \\
\text { Hardly } \\
\text { ever }\end{array}$ & $\begin{array}{c}3 \\
\text { Sometimes }\end{array}$ & $\begin{array}{c}4 \\
\text { Most } \\
\text { of } \\
\text { the } \\
\text { time }\end{array}$ & $\begin{array}{c}5 \\
\text { All of } \\
\text { the } \\
\text { time }\end{array}$ \\
\hline $\begin{array}{l}\text { 6. I feel that other kids talk about me } \\
\text { behind my back. }\end{array}$ & $\begin{array}{c}1 \\
\text { Not } \\
\text { at } \\
\text { all }\end{array}$ & $\begin{array}{c}2 \\
\text { Hardly } \\
\text { ever }\end{array}$ & $\begin{array}{c}3 \\
\text { Sometimes }\end{array}$ & $\begin{array}{c}4 \\
\text { Most } \\
\text { of } \\
\text { the } \\
\text { time }\end{array}$ & $\begin{array}{c}5 \\
\text { All of } \\
\text { the } \\
\text { time }\end{array}$ \\
\hline 7. I worry that other kids don't like me. & $\begin{array}{c}1 \\
\text { Not } \\
\text { at } \\
\text { all }\end{array}$ & $\begin{array}{c}2 \\
\text { Hardly } \\
\text { ever }\end{array}$ & $\begin{array}{c}3 \\
\text { Sometimes }\end{array}$ & $\begin{array}{c}4 \\
\text { Most } \\
\text { of } \\
\text { the } \\
\text { time }\end{array}$ & $\begin{array}{c}5 \\
\text { All of } \\
\text { the } \\
\text { time }\end{array}$ \\
\hline $\begin{array}{l}\text { 8. If I get into an argument with another } \\
\text { kid, I worry that he or she won't like me. }\end{array}$ & $\begin{array}{c}1 \\
\text { Not } \\
\text { at } \\
\text { all }\end{array}$ & $\begin{array}{c}2 \\
\text { Hardly } \\
\text { ever }\end{array}$ & $\begin{array}{c}3 \\
\text { Sometimes }\end{array}$ & $\begin{array}{c}4 \\
\text { Most } \\
\text { of } \\
\text { the } \\
\text { time }\end{array}$ & $\begin{array}{c}5 \\
\text { All of } \\
\text { the } \\
\text { time }\end{array}$ \\
\hline $\begin{array}{l}\text { 9. I worry about doing something new in } \\
\text { front of other kids. }\end{array}$ & $\begin{array}{c}1 \\
\text { Not } \\
\text { at } \\
\text { all }\end{array}$ & $\begin{array}{c}2 \\
\text { Hardly } \\
\text { ever }\end{array}$ & $\begin{array}{c}3 \\
\text { Sometimes }\end{array}$ & $\begin{array}{c}4 \\
\text { Most } \\
\text { of } \\
\text { the } \\
\text { time }\end{array}$ & $\begin{array}{c}5 \\
\text { All of } \\
\text { the } \\
\text { time }\end{array}$ \\
\hline
\end{tabular}


The next questions ask you about how you feel around other kids. Please circle the answer that best describes YOU!

\begin{tabular}{|c|c|c|c|c|c|}
\hline 10. I feel shy around kids I don't know. & $\begin{array}{c}1 \\
\text { Not } \\
\text { at } \\
\text { all }\end{array}$ & $\begin{array}{c}2 \\
\text { Hardly } \\
\text { ever }\end{array}$ & $\begin{array}{c}3 \\
\text { Sometimes }\end{array}$ & $\begin{array}{c}4 \\
\text { Most } \\
\text { of } \\
\text { the } \\
\text { time }\end{array}$ & $\begin{array}{c}5 \\
\text { All of } \\
\text { the } \\
\text { time }\end{array}$ \\
\hline 11. I only talk to kids I know really well. & $\begin{array}{c}1 \\
\text { Not } \\
\text { at } \\
\text { all }\end{array}$ & $\begin{array}{c}2 \\
\text { Hardly } \\
\text { ever }\end{array}$ & $\begin{array}{c}3 \\
\text { Sometimes }\end{array}$ & $\begin{array}{c}4 \\
\text { Most } \\
\text { of } \\
\text { the } \\
\text { time }\end{array}$ & $\begin{array}{c}5 \\
\text { All of } \\
\text { the } \\
\text { time }\end{array}$ \\
\hline 12. I get nervous when I talk to new kids. & $\begin{array}{c}1 \\
\text { Not } \\
\text { at } \\
\text { all }\end{array}$ & $\begin{array}{c}2 \\
\text { Hardly } \\
\text { ever }\end{array}$ & $\begin{array}{c}3 \\
\text { Sometimes }\end{array}$ & $\begin{array}{c}4 \\
\text { Most } \\
\text { of } \\
\text { the } \\
\text { time }\end{array}$ & $\begin{array}{c}5 \\
\text { All of } \\
\text { the } \\
\text { time }\end{array}$ \\
\hline $\begin{array}{l}\text { 13. I feel nervous when I'm around } \\
\text { certain kids. }\end{array}$ & $\begin{array}{c}1 \\
\text { Not } \\
\text { at } \\
\text { all }\end{array}$ & $\begin{array}{c}2 \\
\text { Hardly } \\
\text { ever }\end{array}$ & $\begin{array}{c}3 \\
\text { Sometimes }\end{array}$ & $\begin{array}{c}4 \\
\text { Most } \\
\text { of } \\
\text { the } \\
\text { time }\end{array}$ & $\begin{array}{c}5 \\
\text { All of } \\
\text { the } \\
\text { time }\end{array}$ \\
\hline $\begin{array}{l}\text { 14. I get nervous when I talk to kids I } \\
\text { don't know very well. }\end{array}$ & $\begin{array}{c}1 \\
\text { Not } \\
\text { at } \\
\text { all }\end{array}$ & $\begin{array}{c}2 \\
\text { Hardly } \\
\text { ever }\end{array}$ & $\begin{array}{c}3 \\
\text { Sometimes }\end{array}$ & $\begin{array}{c}4 \\
\text { Most } \\
\text { of } \\
\text { the } \\
\text { time }\end{array}$ & $\begin{array}{c}5 \\
\text { All of } \\
\text { the } \\
\text { time }\end{array}$ \\
\hline $\begin{array}{l}\text { 15. I am quiet when I'm with a group of } \\
\text { kids. }\end{array}$ & $\begin{array}{c}1 \\
\text { Not } \\
\text { at } \\
\text { all }\end{array}$ & $\begin{array}{c}2 \\
\text { Hardly } \\
\text { ever }\end{array}$ & $\begin{array}{c}3 \\
\text { Sometimes }\end{array}$ & $\begin{array}{c}4 \\
\text { Most } \\
\text { of } \\
\text { the } \\
\text { time }\end{array}$ & $\begin{array}{c}5 \\
\text { All of } \\
\text { the } \\
\text { time }\end{array}$ \\
\hline $\begin{array}{l}\text { 16. I feel shy even with kids I know very } \\
\text { well. }\end{array}$ & $\begin{array}{c}1 \\
\text { Not } \\
\text { at } \\
\text { all }\end{array}$ & $\begin{array}{c}2 \\
\text { Hardly } \\
\text { ever }\end{array}$ & $\begin{array}{c}3 \\
\text { Sometimes }\end{array}$ & $\begin{array}{c}4 \\
\text { Most } \\
\text { of } \\
\text { the } \\
\text { time }\end{array}$ & $\begin{array}{c}5 \\
\text { All of } \\
\text { the } \\
\text { time }\end{array}$ \\
\hline $\begin{array}{l}\text { 17. It's hard for me to ask other kids to } \\
\text { play with me. }\end{array}$ & $\begin{array}{c}1 \\
\text { Not } \\
\text { at } \\
\text { all }\end{array}$ & $\begin{array}{c}2 \\
\text { Hardly } \\
\text { ever }\end{array}$ & $\begin{array}{c}3 \\
\text { Sometimes }\end{array}$ & $\begin{array}{c}4 \\
\text { Most } \\
\text { of } \\
\text { the } \\
\text { time }\end{array}$ & $\begin{array}{c}5 \\
\text { All of } \\
\text { the } \\
\text { time }\end{array}$ \\
\hline
\end{tabular}


Approach, Avoidance, and Psychopathology 74

\begin{tabular}{|l|c|c|c|c|c|}
\hline $\begin{array}{l}\text { 18. I'm afraid to invite others to my house } \\
\text { because they might say no. }\end{array}$ & $\begin{array}{c}1 \\
\text { Not } \\
\text { at } \\
\text { all }\end{array}$ & $\begin{array}{c}2 \\
\text { Hardly } \\
\text { ever }\end{array}$ & Sometimes & $\begin{array}{c}4 \\
\text { Most } \\
\text { of } \\
\text { the } \\
\text { time }\end{array}$ & $\begin{array}{c}5 \\
\text { All of } \\
\text { the } \\
\text { time }\end{array}$ \\
\hline
\end{tabular}


Appendix D - Child Depression Inventory

\section{The Way You Feel}

These questions ask you about how you have been feeling lately.

Please circle the answer that best describes YOU!

\begin{tabular}{|c|c|}
\hline $\begin{array}{l}\text { I. } \\
\text { I am sad once in a while. } \\
\text { I am sad all the time. }\end{array}$ & $\begin{array}{l}6 . \\
\text { Things bother me all the time. } \\
\text { Things bother me many times. } \\
\text { Things bother me once in a while. }\end{array}$ \\
\hline $\begin{array}{l}2 . \\
\text { Nothing will ever work out for me. } \\
\text { I am not sure if things will work out } \\
\text { for me. } \\
\text { Things will work out for me O.K. }\end{array}$ & $\begin{array}{l}7 . \\
\text { I look O.K. } \\
\text { There are some bad things about my } \\
\text { looks. } \\
\text { I look ugly. }\end{array}$ \\
\hline $\begin{array}{l}\text { I. } \\
\text { I do most things O.K. } \\
\text { I do many things wrong. } \\
\text { I do everything wrong. }\end{array}$ & $\begin{array}{l}8 . \\
\text { I do not feel alone. } \\
\text { I feel alone many times. } \\
\text { I feel alone all the time. }\end{array}$ \\
\hline $\begin{array}{l}4 . \\
\text { I hate myself. } \\
\text { I do not like myself. } \\
\text { I like myself. }\end{array}$ & $\begin{array}{l}9 . \\
\text { I have plenty of friends. } \\
\text { I have some friends but I wish I had } \\
\text { more. } \\
\text { I do not have any friends. }\end{array}$ \\
\hline $\begin{array}{l}5 . \\
\text { I feel like crying everyday. } \\
\text { I feel like crying many days. } \\
\text { I feel like crying once in a while. }\end{array}$ & $\begin{array}{l}10 . \\
\text { Nobody really loves me. } \\
\text { I am not sure if anybody loves me. } \\
\text { I am sure that somebody loves me. }\end{array}$ \\
\hline
\end{tabular}


Appendix E - Loneliness and Social Dissatisfaction Questionnaire

\section{How I Get Along With Others}

The next questions ask you about how you get along with other kids. For each question circle the answer that best describes YOU!

$1=$ Always true, 2 = Mostly true, $3=$ Sometimes true, $4=$ Hardly true, $5=$ Never true

\begin{tabular}{|c|c|c|c|c|c|}
\hline $\begin{array}{l}\text { 1. It is easy for me to make new } \\
\text { friends at school. }\end{array}$ & $\begin{array}{c}1 \\
\text { Always } \\
\text { True } \\
\end{array}$ & $\begin{array}{c}2 \\
\text { Mostly } \\
\text { True }\end{array}$ & $\begin{array}{c}3 \\
\text { Sometimes } \\
\text { True }\end{array}$ & $\begin{array}{c}4 \\
\text { Hardly } \\
\text { True } \\
\end{array}$ & $\begin{array}{c}5 \\
\text { Never } \\
\text { True } \\
\end{array}$ \\
\hline 2. I like to read. & $\begin{array}{c}1 \\
\text { Always } \\
\text { True }\end{array}$ & $\begin{array}{c}2 \\
\text { Mostly } \\
\text { True }\end{array}$ & $\begin{array}{c}3 \\
\text { Sometimes } \\
\text { True }\end{array}$ & $\begin{array}{c}4 \\
\text { Hardly } \\
\text { True }\end{array}$ & $\begin{array}{c}5 \\
\text { Never } \\
\text { True }\end{array}$ \\
\hline 3. I have nobody to & $\begin{array}{c}1 \\
\text { Always } \\
\text { True } \\
\end{array}$ & $\begin{array}{c}2 \\
\text { Mostly } \\
\text { True }\end{array}$ & $\begin{array}{c}3 \\
\text { Sometimes } \\
\text { True } \\
\end{array}$ & $\begin{array}{c} \\
\text { Hardly } \\
\text { True }\end{array}$ & $\begin{array}{c}5 \\
\text { Never } \\
\text { True } \\
\end{array}$ \\
\hline $\begin{array}{l}\text { 4. I am good at working with other } \\
\text { children. }\end{array}$ & $\begin{array}{c}1 \\
\text { Always } \\
\text { True } \\
\end{array}$ & $\begin{array}{c}2 \\
\text { Mostly } \\
\text { True }\end{array}$ & $\begin{array}{c}3 \\
\text { Sometimes } \\
\text { True } \\
\end{array}$ & $\begin{array}{c}4 \\
\text { Hardly } \\
\text { True } \\
\end{array}$ & $\begin{array}{c}5 \\
\text { Never } \\
\text { True } \\
\end{array}$ \\
\hline 5. I wat & $\begin{array}{c}1 \\
\text { Always } \\
\text { True }\end{array}$ & $\begin{array}{c}2 \\
\text { Mostly } \\
\text { True }\end{array}$ & $\begin{array}{c}3 \\
\text { Sometimes } \\
\text { True } \\
\end{array}$ & $\begin{array}{c}4 \\
\text { Hardly } \\
\text { True } \\
\end{array}$ & $\begin{array}{c}5 \\
\text { Never } \\
\text { True } \\
\end{array}$ \\
\hline 6. It is $h$ & $\begin{array}{c}1 \\
\text { Always } \\
\text { True } \\
\end{array}$ & $\begin{array}{c}2 \\
\text { Mostly } \\
\text { True }\end{array}$ & $\begin{array}{c}3 \\
\text { Sometimes } \\
\text { True } \\
\end{array}$ & $\begin{array}{c}4 \\
\text { Hardly } \\
\text { True } \\
\end{array}$ & $\begin{array}{c}5 \\
\text { Never } \\
\text { True } \\
\end{array}$ \\
\hline 7. I like school. & $\begin{array}{c}1 \\
\text { Always } \\
\text { True } \\
\end{array}$ & $\begin{array}{c}2 \\
\text { Mostly } \\
\text { True }\end{array}$ & $\begin{array}{c}3 \\
\text { Sometimes } \\
\text { True } \\
\end{array}$ & $\begin{array}{c}4 \\
\text { Hardly } \\
\text { True } \\
\end{array}$ & $\begin{array}{c}5 \\
\text { Never } \\
\text { True } \\
\end{array}$ \\
\hline 8. I have lots of friends. & $\begin{array}{c}1 \\
\text { Always } \\
\text { True } \\
\end{array}$ & $\begin{array}{c}2 \\
\text { Mostly } \\
\text { True }\end{array}$ & $\begin{array}{c}3 \\
\text { Sometimes } \\
\text { True } \\
\end{array}$ & $\begin{array}{c}4 \\
\text { Hardly } \\
\text { True } \\
\end{array}$ & $\begin{array}{c}5 \\
\text { Never } \\
\text { True } \\
\end{array}$ \\
\hline 9. I feel alone. & $\begin{array}{c}1 \\
\text { Always } \\
\text { True }\end{array}$ & $\begin{array}{c}2 \\
\text { Mostly } \\
\text { True }\end{array}$ & $\begin{array}{c}3 \\
\text { Sometimes } \\
\text { True }\end{array}$ & $\begin{array}{c}4 \\
\text { Hardly } \\
\text { True }\end{array}$ & $\begin{array}{c}5 \\
\text { Never } \\
\text { True }\end{array}$ \\
\hline
\end{tabular}

\begin{tabular}{|c|c|c|c|c|c|}
\hline 10. I can find a friend when I need one. & $\begin{array}{c}1 \\
\text { Always } \\
\text { True }\end{array}$ & $\begin{array}{c}2 \\
\text { Mostly } \\
\text { True }\end{array}$ & $\begin{array}{c}3 \\
\text { Sometimes } \\
\text { True }\end{array}$ & $\begin{array}{c}4 \\
\text { Hardly } \\
\text { True }\end{array}$ & $\begin{array}{c}5 \\
\text { Never } \\
\text { True }\end{array}$ \\
\hline $11 . \mathrm{I} \mathrm{p}$ & $\begin{array}{c}1 \\
\text { Always } \\
\text { True }\end{array}$ & $\begin{array}{c}2 \\
\text { Mostly } \\
\text { True }\end{array}$ & $\begin{array}{c}3 \\
\text { Sometimes } \\
\text { True }\end{array}$ & $\begin{array}{c}4 \\
\text { Hardly } \\
\text { True }\end{array}$ & $\begin{array}{c}5 \\
\text { Never } \\
\text { True }\end{array}$ \\
\hline $\begin{array}{l}\text { 12. It is hard to get other kids to like } \\
\text { me. }\end{array}$ & $\begin{array}{c}1 \\
\text { Always } \\
\text { True }\end{array}$ & $\begin{array}{c}2 \\
\text { Mostly } \\
\text { True }\end{array}$ & $\begin{array}{c}3 \\
\text { Sometimes } \\
\text { True }\end{array}$ & $\begin{array}{c}4 \\
\text { Hardly } \\
\text { True }\end{array}$ & $\begin{array}{c}5 \\
\text { Never } \\
\text { True }\end{array}$ \\
\hline 13. I like & $\begin{array}{c}1 \\
\text { Always }\end{array}$ & $\begin{array}{c}2 \\
\text { Mostly }\end{array}$ & $\begin{array}{c}3 \\
\text { Sometimes }\end{array}$ & $\begin{array}{c}4 \\
\text { Hardly } \\
\end{array}$ & $\begin{array}{c}5 \\
\text { Never }\end{array}$ \\
\hline
\end{tabular}




\begin{tabular}{|c|c|c|c|c|c|}
\hline & True & True & True & True & True \\
\hline 14. I do not have anyone to play with. & $\begin{array}{c}1 \\
\text { Always } \\
\text { True }\end{array}$ & $\begin{array}{c}2 \\
\text { Mostly } \\
\text { True }\end{array}$ & $\begin{array}{c}3 \\
\text { Sometimes } \\
\text { True }\end{array}$ & $\begin{array}{c}4 \\
\text { Hardly } \\
\text { True }\end{array}$ & $\begin{array}{c}5 \\
\text { Never } \\
\text { True }\end{array}$ \\
\hline 15. I like music. & $\begin{array}{c}1 \\
\text { Always } \\
\text { True } \\
\end{array}$ & $\begin{array}{c}2 \\
\text { Mostly } \\
\text { True }\end{array}$ & $\begin{array}{c}3 \\
\text { Sometimes } \\
\text { True }\end{array}$ & $\begin{array}{c}4 \\
\text { Hardly } \\
\text { True }\end{array}$ & $\begin{array}{c}5 \\
\text { Never } \\
\text { True }\end{array}$ \\
\hline 16. I get along with other kids. & $\begin{array}{c}1 \\
\text { Always } \\
\text { True } \\
\end{array}$ & $\begin{array}{c}2 \\
\text { Mostly } \\
\text { True }\end{array}$ & $\begin{array}{c}3 \\
\text { Sometimes } \\
\text { True } \\
\end{array}$ & $\begin{array}{c}4 \\
\text { Hardly } \\
\text { True }\end{array}$ & $\begin{array}{c}5 \\
\text { Never } \\
\text { True } \\
\end{array}$ \\
\hline 17. I feel left out of things. & $\begin{array}{c}1 \\
\text { Always } \\
\text { True } \\
\end{array}$ & $\begin{array}{c}2 \\
\text { Mostly } \\
\text { True }\end{array}$ & $\begin{array}{c}3 \\
\text { Sometimes } \\
\text { True } \\
\end{array}$ & $\begin{array}{c}4 \\
\text { Hardly } \\
\text { True }\end{array}$ & $\begin{array}{c}5 \\
\text { Never } \\
\text { True } \\
\end{array}$ \\
\hline $\begin{array}{l}\text { 18. There is nobody I can go to when I } \\
\text { need help. }\end{array}$ & $\begin{array}{c}1 \\
\text { Always } \\
\text { True } \\
\end{array}$ & $\begin{array}{c}2 \\
\text { Mostly } \\
\text { True } \\
\end{array}$ & $\begin{array}{c}3 \\
\text { Sometimes } \\
\text { True }\end{array}$ & $\begin{array}{c}4 \\
\text { Hardly } \\
\text { True }\end{array}$ & $\begin{array}{c}5 \\
\text { Never } \\
\text { True } \\
\end{array}$ \\
\hline 19. I like & $\begin{array}{c}1 \\
\text { Always } \\
\text { True } \\
\end{array}$ & $\begin{array}{c}2 \\
\text { Mostly } \\
\text { True }\end{array}$ & $\begin{array}{c}3 \\
\text { Sometimes } \\
\text { True } \\
\end{array}$ & $\begin{array}{c}4 \\
\text { Hardly } \\
\text { True }\end{array}$ & $\begin{array}{c}5 \\
\text { Never } \\
\text { True }\end{array}$ \\
\hline $\begin{array}{l}\text { 20. I do not get along with other } \\
\text { children }\end{array}$ & $\begin{array}{c}1 \\
\text { Always } \\
\text { True } \\
\end{array}$ & $\begin{array}{c}2 \\
\text { Mostly } \\
\text { True } \\
\end{array}$ & $\begin{array}{c}3 \\
\text { Sometimes } \\
\text { True } \\
\end{array}$ & $\begin{array}{c}4 \\
\text { Hardly } \\
\text { True }\end{array}$ & $\begin{array}{c}5 \\
\text { Never } \\
\text { True } \\
\end{array}$ \\
\hline 21. I am lonely. & $\begin{array}{c}1 \\
\text { Always } \\
\text { True }\end{array}$ & $\begin{array}{c}2 \\
\text { Mostly } \\
\text { True }\end{array}$ & $\begin{array}{c}3 \\
\text { Sometimes } \\
\text { True }\end{array}$ & $\begin{array}{c}4 \\
\text { Hardly } \\
\text { True }\end{array}$ & $\begin{array}{c}5 \\
\text { Never } \\
\text { True }\end{array}$ \\
\hline $\begin{array}{l}\text { 22. I am well-liked by the kids in my } \\
\text { class. }\end{array}$ & $\begin{array}{c}1 \\
\text { Always } \\
\text { True }\end{array}$ & $\begin{array}{c}2 \\
\text { Mostly } \\
\text { True }\end{array}$ & $\begin{array}{c}3 \\
\text { Sometimes } \\
\text { True }\end{array}$ & $\begin{array}{c}4 \\
\text { Hardly } \\
\text { True } \\
\end{array}$ & $\begin{array}{c}5 \\
\text { Never } \\
\text { True }\end{array}$ \\
\hline 23. I like playing board games a lot. & $\begin{array}{c}1 \\
\text { Always } \\
\text { True } \\
\end{array}$ & $\begin{array}{c}2 \\
\text { Mostly } \\
\text { True } \\
\end{array}$ & $\begin{array}{c}3 \\
\text { Sometimes } \\
\text { True } \\
\end{array}$ & $\begin{array}{c}4 \\
\text { Hardly } \\
\text { True }\end{array}$ & $\begin{array}{c}5 \\
\text { Never } \\
\text { True }\end{array}$ \\
\hline 24. I do not have any friends. & $\begin{array}{c}1 \\
\text { Always } \\
\text { True } \\
\end{array}$ & $\begin{array}{c}2 \\
\text { Mostly } \\
\text { True } \\
\end{array}$ & $\begin{array}{c}3 \\
\text { Sometimes } \\
\text { True } \\
\end{array}$ & $\begin{array}{c}4 \\
\text { Hardly } \\
\text { True } \\
\end{array}$ & $\begin{array}{c}5 \\
\text { Never } \\
\text { True } \\
\end{array}$ \\
\hline
\end{tabular}


Appendix F - Self-Description Questionnaire

All About Me

The next questions ask you about yourself! Circle the answer that best describes YOU! $1=$ False, $2=$ Mostly false, $3=$ Sometimes false, $4=$ Mostly true, $5=$ True

\begin{tabular}{|c|c|c|c|c|c|}
\hline 1. I have lots of friends. & $\begin{array}{c}1 \\
\text { False }\end{array}$ & $\begin{array}{c}2 \\
\text { Mostly } \\
\text { False }\end{array}$ & $\begin{array}{c}3 \\
\text { Sometimes } \\
\text { False }\end{array}$ & $\begin{array}{c}4 \\
\text { Mostly } \\
\text { True }\end{array}$ & $\begin{array}{c}5 \\
\text { True }\end{array}$ \\
\hline 2. I make friends easily. & $\begin{array}{c}1 \\
\text { False }\end{array}$ & $\begin{array}{c}2 \\
\text { Mostly } \\
\text { False }\end{array}$ & $\begin{array}{c}3 \\
\text { Sometimes } \\
\text { False }\end{array}$ & $\begin{array}{c}4 \\
\text { Mostly } \\
\text { True }\end{array}$ & $\begin{array}{c}5 \\
\text { True }\end{array}$ \\
\hline 3. Most kids have more friends than I do. & $\begin{array}{c}1 \\
\text { False }\end{array}$ & $\begin{array}{c}2 \\
\text { Mostly } \\
\text { False }\end{array}$ & $\begin{array}{c}3 \\
\text { Sometimes } \\
\text { False }\end{array}$ & $\begin{array}{c}4 \\
\text { Mostly } \\
\text { True }\end{array}$ & $\begin{array}{c}5 \\
\text { True }\end{array}$ \\
\hline 4. I get & $\begin{array}{c}1 \\
\text { False }\end{array}$ & $\begin{array}{c}2 \\
\text { Mostly } \\
\text { False }\end{array}$ & $\begin{array}{c}3 \\
\text { Sometimes } \\
\text { False }\end{array}$ & $\begin{array}{c}4 \\
\text { Mostly } \\
\text { True }\end{array}$ & $\begin{array}{c}5 \\
\text { True }\end{array}$ \\
\hline 5. I am easy to like. & $\begin{array}{c}1 \\
\text { False }\end{array}$ & $\begin{array}{c}2 \\
\text { Mostly } \\
\text { False }\end{array}$ & $\begin{array}{c}3 \\
\text { Sometimes } \\
\text { False } \\
\end{array}$ & $\begin{array}{c}4 \\
\text { Mostly } \\
\text { True } \\
\end{array}$ & $\begin{array}{c}5 \\
\text { True }\end{array}$ \\
\hline 6. Othe & $\begin{array}{c}1 \\
\text { False }\end{array}$ & $\begin{array}{c}2 \\
\text { Mostly } \\
\text { False }\end{array}$ & $\begin{array}{c}3 \\
\text { Sometimes } \\
\text { False }\end{array}$ & $\begin{array}{c}4 \\
\text { Mostly } \\
\text { True }\end{array}$ & $\begin{array}{c}5 \\
\text { True }\end{array}$ \\
\hline $\begin{array}{l}\text { 7. I have more friends than most other } \\
\text { kids. }\end{array}$ & $\begin{array}{c}1 \\
\text { False }\end{array}$ & $\begin{array}{c}2 \\
\text { Mostly } \\
\text { False }\end{array}$ & $\begin{array}{c}3 \\
\text { Sometimes } \\
\text { False }\end{array}$ & $\begin{array}{c}4 \\
\text { Mostly } \\
\text { True }\end{array}$ & $\begin{array}{c}5 \\
\text { True }\end{array}$ \\
\hline opular with kids of my & $\begin{array}{c}1 \\
\text { False }\end{array}$ & $\begin{array}{c}2 \\
\text { Mostly } \\
\text { False }\end{array}$ & $\begin{array}{c}3 \\
\text { Sometimes } \\
\text { False }\end{array}$ & $\begin{array}{c}4 \\
\text { Mostly } \\
\text { True }\end{array}$ & $\begin{array}{c}5 \\
\text { True }\end{array}$ \\
\hline 9. Most other kids like me. & $\begin{array}{c}1 \\
\text { False }\end{array}$ & $\begin{array}{c}2 \\
\text { Mostly } \\
\text { False }\end{array}$ & $\begin{array}{c}3 \\
\text { Sometimes } \\
\text { False }\end{array}$ & $\begin{array}{c}4 \\
\text { Mostly } \\
\text { True }\end{array}$ & $\begin{array}{c}5 \\
\text { True }\end{array}$ \\
\hline 10. I am good at all school subjects. & $\begin{array}{c}1 \\
\text { False }\end{array}$ & $\begin{array}{c}2 \\
\text { Mostly } \\
\text { False }\end{array}$ & $\begin{array}{c}3 \\
\text { Sometimes } \\
\text { False }\end{array}$ & $\begin{array}{c}4 \\
\text { Mostly } \\
\text { True }\end{array}$ & $\begin{array}{c}5 \\
\text { True }\end{array}$ \\
\hline $\begin{array}{l}11 . \text { I enjoy doing work in all school } \\
\text { subjects. }\end{array}$ & $\begin{array}{c}1 \\
\text { False }\end{array}$ & $\begin{array}{c}2 \\
\text { Mostly } \\
\text { False }\end{array}$ & $\begin{array}{c}3 \\
\text { Sometimes } \\
\text { False }\end{array}$ & $\begin{array}{c}4 \\
\text { Mostly } \\
\text { True }\end{array}$ & $\begin{array}{c}5 \\
\text { True }\end{array}$ \\
\hline
\end{tabular}

\begin{tabular}{|l|c|c|c|c|c|}
\hline 12. I get good marks in all school subjects. & $\begin{array}{c}1 \\
\text { False }\end{array}$ & $\begin{array}{c}2 \\
\text { Mostly } \\
\text { False }\end{array}$ & $\begin{array}{c}3 \\
\text { Sometimes } \\
\text { False }\end{array}$ & $\begin{array}{c}4 \\
\text { Mostly } \\
\text { True }\end{array}$ & $\begin{array}{c}5 \\
\text { True }\end{array}$ \\
\hline 13. I hate all school subjects. & 1 & 2 & 3 & 4 & 5 \\
& False & Mostly & Sometimes & Mostly & True \\
\hline
\end{tabular}




\begin{tabular}{|c|c|c|c|c|c|}
\hline & & False & False & True & \\
\hline $\begin{array}{l}\text { 14. I learn things quickly in all school } \\
\text { subjects. }\end{array}$ & $\begin{array}{c}1 \\
\text { False }\end{array}$ & $\begin{array}{c}2 \\
\text { Mostly } \\
\text { False }\end{array}$ & $\begin{array}{c}3 \\
\text { Sometimes } \\
\text { False }\end{array}$ & $\begin{array}{c}4 \\
\text { Mostly } \\
\text { True }\end{array}$ & $\begin{array}{c}5 \\
\text { True }\end{array}$ \\
\hline 15. I am & $\begin{array}{c}1 \\
\text { False }\end{array}$ & $\begin{array}{c}2 \\
\text { Mostly } \\
\text { False }\end{array}$ & $\begin{array}{c}3 \\
\text { Sometimes } \\
\text { False }\end{array}$ & $\begin{array}{c}4 \\
\text { Mostly } \\
\text { True }\end{array}$ & $\begin{array}{c}5 \\
\text { True }\end{array}$ \\
\hline 16. I am bad in all school subjects. & $\begin{array}{c}1 \\
\text { False }\end{array}$ & $\begin{array}{c}2 \\
\text { Mostly } \\
\text { False }\end{array}$ & $\begin{array}{c}3 \\
\text { Sometimes } \\
\text { False }\end{array}$ & $\begin{array}{c}4 \\
\text { Mostly } \\
\text { True }\end{array}$ & $\begin{array}{c}5 \\
\text { True }\end{array}$ \\
\hline 17. I loc & $\begin{array}{c}1 \\
\text { False }\end{array}$ & $\begin{array}{c}2 \\
\text { Mostly } \\
\text { False }\end{array}$ & $\begin{array}{c}3 \\
\text { Sometimes } \\
\text { False }\end{array}$ & $\begin{array}{c}4 \\
\text { Mostly } \\
\text { True }\end{array}$ & $\begin{array}{c}5 \\
\text { True }\end{array}$ \\
\hline $\begin{array}{l}\text { 18. Work in all school subjects is easy for } \\
\text { me. }\end{array}$ & $\begin{array}{c}1 \\
\text { False }\end{array}$ & $\begin{array}{c}2 \\
\text { Mostly } \\
\text { False }\end{array}$ & $\begin{array}{c}3 \\
\text { Sometimes } \\
\text { False }\end{array}$ & $\begin{array}{c}4 \\
\text { Mostly } \\
\text { True }\end{array}$ & $\begin{array}{c}5 \\
\text { True }\end{array}$ \\
\hline 19. I like all school subjects. & $\begin{array}{c}1 \\
\text { False }\end{array}$ & $\begin{array}{c}2 \\
\text { Mostly } \\
\text { False }\end{array}$ & $\begin{array}{c}3 \\
\text { Sometimes } \\
\text { False }\end{array}$ & $\begin{array}{c}4 \\
\text { Mostly } \\
\text { True }\end{array}$ & $\begin{array}{c}5 \\
\text { True }\end{array}$ \\
\hline
\end{tabular}


Appendix G - Strengths and Difficulties Questionnaire

\begin{tabular}{|c|c|}
\hline Not & Somewhat \\
\hline
\end{tabular}

1. Considerate of other people's feelings.

2. Often complains of headaches, stomach-aches or sickness.

3. Shares readily with other children (treats, toys, pencils, etc.).

4. Often has temper tantrums or hot tempers.

5. Rather solitary, tends to play alone.

6. Generally obedient, usually does what adults request.

7. Many worries, often seems worried.

8. Helpful if someone is hurt, upset, or feeling ill.

9. Has at lease one good friend.

10. Often fights with other children or bullies them.

11. Often unhappy, down hearted or tearful.

12. Generally liked by other children.

13. Nervous or clingy in new situations, easily loses confidence.

14. Kind to younger children.

15. Often lies or cheats.

16. Picked on or bullied by other children.

17. Often volunteers to help others (parents, teachers, children).

18. Steals from home, school, or elsewhere.

19. Gets on better with adults than with other children.

20. Many fears, easily scared. 